\title{
Scrape-Off Layer Transport and Deposition Studies in DIII-D
}

M. Groth, S.L. Allen, J.A. Boedo, N.H. Brooks, J.D. Elder, M.E. Fenstermacher, R.J. Groebner, C.J. Lasnier, A.G. McLean, A.W. Leonard, S. Lisgo, G.D. Porter, M.E. Rensink, T.D. Rognlien, D.L. Rudakov, P.C. Stangeby, W.R. Wampler, J.G. Watkins, W.P.West, D.G. Whyte

October 30, 2006

48th Annual APS DPP

Philadelphia, PA, United States

October 30, 2006 through November 3, 2006 
This document was prepared as an account of work sponsored by an agency of the United States Government. Neither the United States Government nor the University of California nor any of their employees, makes any warranty, express or implied, or assumes any legal liability or responsibility for the accuracy, completeness, or usefulness of any information, apparatus, product, or process disclosed, or represents that its use would not infringe privately owned rights. Reference herein to any specific commercial product, process, or service by trade name, trademark, manufacturer, or otherwise, does not necessarily constitute or imply its endorsement, recommendation, or favoring by the United States Government or the University of California. The views and opinions of authors expressed herein do not necessarily state or reflect those of the United States Government or the University of California, and shall not be used for advertising or product endorsement purposes. 


\title{
Scrape-off layer transport and deposition studies in DIII-D
}

\author{
M. Groth, ${ }^{* a}$ S.L. Allen, ${ }^{\text {a J.A. Boedo, }}{ }^{\mathrm{b}}$ N.H. Brooks, ${ }^{\mathrm{c}}$ J.D. Elder, ${ }^{\mathrm{d}}$ M.E. Fenstermacher, ${ }^{\mathrm{a}}$

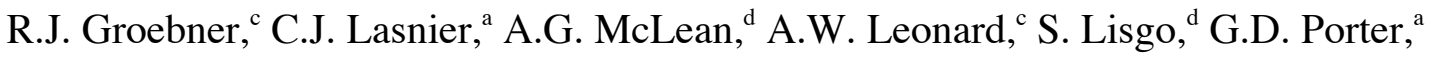 \\ M.E. Rensink, ${ }^{\mathrm{a}}$ T.D. Rognlien, ${ }^{\mathrm{a}}$ D.L. Rudakov, ${ }^{\mathrm{b}}$ P.C. Stangeby, ${ }^{\mathrm{d}}$ W.R. Wampler, \\ J.G. Watkins, ${ }^{e}$ W.P. West, ${ }^{c}$ and D.G. Whyte ${ }^{f}$ \\ ${ }^{a}$ Lawrence Livermore National Laboratory, Livermore, California, 94550, USA \\ ${ }^{b}$ University of California, San Diego, La Jolla, California, USA \\ ${ }^{c}$ General Atomics, P.O. Box 85608, San Diego, California, 92186, USA \\ ${ }^{d}$ University of Toronto Institute for Aerospace Studies, Toronto, Canada \\ ${ }^{e}$ Sandia National Laboratory, Albuquerque, New Mexico, USA \\ ${ }^{f}$ Massachusetts Institute of Technology, Cambridge, Massachusetts, USA
}

Trace ${ }^{13} \mathrm{CH}_{4}$ injection experiments into the main scrape-off layer of low density L-mode and high-density H-mode plasmas have been performed in the DIII-D tokamak [Luxon_NF02] to mimic the transport and deposition of carbon arising from a main chamber sputtering source. These experiments indicated entrainment of the injected carbon in plasma flow in the main SOL, and transport toward the inner divertor. Ex-situ surface analysis showed enhanced ${ }^{13} \mathrm{C}$ surface concentration at the corner formed by the divertor floor and the angled target plate of the inner divertor in L-mode; in H-mode, both at the corner and along the surface bounding the private flux region inboard of the outer strike point. Interpretative modeling was made consistent with these experimental results by imposing a parallel carbon ion flow in the main SOL toward the inner target, and a radial pinch toward the separatrix. Predictive modeling carried out to better understand the underlying plasma transport processes suggests that the deuterium flow in the main SOL is related to the degree of detachment of the inner divertor leg. These simulations show that carbon ions are entrained with the deuteron flow in the main SOL via frictional coupling, but higher charge state carbon ions may be suspended upstream of the inner 
divertor X-point region due to balance of the friction force and the ion temperature gradient.

PACS: 52.55.Fa, 52.40.Hf, 52.65.Kj, 52.65.Pp

*Corresponding and presenting author address: General Atomics, P.O. Box 85608, San Diego, California 92186-5608, USA

*Corresponding and presenting author e-mail: groth@fusion.gat.com 


\section{INTRODUCTION}

Molecular breakup, transport, and deposition of an externally introduced carbon source were studied in the DIII-D tokamak using the carbon isotope of mass 13 in methane as a tracer. Results of the JET deuterium-tritium campaign (DTE1) [Keilhacker_NF99] revealed that significant amounts of tritium accumulated in areas shadowed from the plasma [Andrew_FED99], which underlined the need to better understand the mechanisms leading to fuel retention in fusion devices. Tritium-rich carbon films were found at the water-cooled louver at the entrance of the pumping duct in the JET inner divertor, which connects tritium retention to the issue of long-range carbon migration in fusion devices operating with carbon plasma-facing components (PFCs). In future reactor-relevant fusion devices with carbon PFCs, such as currently foreseen for the divertor target areas in ITER [Federici_NF01], tritium co-deposition can potentially limit reactor duty cycle due to large quantities of tritium being retained inside the vacuum vessel [Brooks_JNM03]. Studying carbon migration in current fusion devices, by experiments and modeling, provides us with a means to elucidate tritium retention in ITER. Such studies may provide a scientific basis to eliminate the tritium retention problem in ITER, by developing scenarios that yield tritium accumulation in areas more accessible to removal techniques.

Operational flexibility and a comprehensive suite of diagnostics on the DIII-D tokamak make it well suited to assess fuel retention caused by carbon migration. Unlike the JET DTE1 results, which were campaign-integrated including a range of plasma conditions and magnetic geometries, injection of tracer gases in DIII-D has provided data unique to a specific plasma and divertor configuration. Since the DIII-D PFCs consist of graphite (Union Carbide isotropic, finegrain ATJ), studying carbon migration in DIII-D in dedicated plasmas requires the injection of carbon isotopes other than the carbon contained in the PFCs. Natural graphite is isotopically $98.9 \%$ carbon of mass $12\left({ }^{12} \mathrm{C}\right)$, and $1.1 \%$ carbon of mass $13\left({ }^{13} \mathrm{C}\right)$. In the experiments described in this paper, ${ }^{13} \mathrm{C}$ was injected in the form of methane, ${ }^{13} \mathrm{CH}_{4}$, at trace levels, to raise ${ }^{13} \mathrm{C}$ 
surface deposition above the naturally occurring background [Allen_JNM05, Wampler_JNM06]. This technique was pioneered at TEXTOR [Wienhold_JNM01], and has since been pursued in other tokamaks also, such as JET [Coad_NF06, Rubel_EPS05], AUG [VainonenAhlgren_JNM05], and JT60-U [Ishimoto_ICFRM05]. Unique to DIII-D, the interpretation of the experimental data was significantly improved by the ability to inject ${ }^{13} \mathrm{CH}_{4}$ in a toroidally symmetric fashion via the outer divertor cryo plenum. Tens of plasma discharges with $\sim 2-3 \mathrm{~s}$ duration of ${ }^{13} \mathrm{CH}_{4}$ injection were typically required to obtain adequate statistics for the ex-situ surface analysis of the graphite tiles.

To mimic a sputtering source in the main chamber, ${ }^{13} \mathrm{CH}_{4}$ was injected into the crown of the plasma, i.e., the scrape-off layer (SOL) and core region opposite of the divertor. This approach was justified by experimental findings in Alcator C-mod [Lipschultz_PPCF05] and DIII-D [Whyte_PPCF05, Rudakov_NF05] that showed significant interaction of the plasma with the main chamber walls occurs in high plasma density operations. In these experiments, the ${ }^{13} \mathrm{CH}_{4}$ injection location closely approximates carbon release at the toroidally symmetric limiter surfaces of the DIII-D upper divertor baffle (Fig. 1). On the other hand, main chamber erosion in DIII-D was shown to be a function of plasma density, thus in low density regimes the main chamber may not be the primary source of carbon in the main SOL [Whyte_PPCF05].

To clarify the controlling physics processes of carbon transport in DIII-D, comprehensive modeling using the OEDGE [Stangeby_JNM03] and UEDGE [Rognlien_JNM92] code packages has been carried out. In general, carbon migration involves (1) primary erosion due to plasma impact on plasma-facing components, (2) transport, dissociation, and ionization of hydrocarbon molecules and carbon atoms, (3) initial deposition, and (4) multi-step re-erosion and redeposition [Matthews_JNM05]. Re-erosion and re-deposition are important, as they can alter the PFC surface composition (e.g., produce amorphous films), and thus its erosion properties, and may lead to carbon migrating into regions shadowed from the plasma. Many of the individual processes are identified and, to some degree of sophistication, implemented in numerical codes 
simulating plasma-surface interaction and plasma transport in the SOL. Integrated modeling of all physics processes, including anomalous radial transport and drifts, however, is still at an early stage, and no code is currently available that consistently includes all of them. The OEDGE package combines the Monte-Carlo code DIVIMP for impurity neutrals and ions with a hydrocarbon model [McLean_JNM05, Elder_JNM06] that tracks the neutral and ionized intermediaries in the dissociative breakup chain of methane. UEDGE is a fluid transport code for electrons, hydrogen and multiple impurity species; it calculates the particle, momentum, and energy balance equations in a consistent manner for all species in the calculational domain.

The OEDGE and UEDGE plasma simulations have been validated against a large set of experimental data. Plasma parameters and emission profiles were measured in the main chamber and divertor SOL with several diagnostics: electron densities and temperatures with Thomson scattering [Carlstrom_RSI92, Carlstrom_RSI97] and Langmuir probes [Watkins_RSI92, Watkins_JNM97], target heat flux with a vertical viewing infra-red camera [Lasnier_NF98], and line emission in the visible wavelength range with a multi-chord line-filtered spectral monitor system [Colchin_RSI03], and a multi-chord spectrometer [Brooks_RSI92]. Plasma imaging using toroidally viewing cameras [Fenstermacher_RSI97, Groth_RSI03] yielded 2-D emission profiles of hydrogen and low charge state carbon in the divertor and inner midplane. Toroidally symmetric injection, unique to DIII-D, permitted tomographic 2-D reconstruction of the hydrocarbon and carbon emission profiles from the crown near the methane injection location.

This paper is structured around the description of two ${ }^{13} \mathrm{C}$ injection experiments in DIII-D (Section II) and their interpretation (Section III). Plasma simulations using the OEDGE and UEDGE codes are described in Section IV. A summary of the experimental and modeling results is provided in Section $\mathrm{V}$. 


\section{TRACE ${ }^{13} \mathrm{CH}_{4}$ INJECTION EXPERIMENTS IN DIII-D}

Trace ${ }^{13} \mathrm{C}$ injection experiments with subsequent, ex-situ tile surface analysis were performed in two types of deuterium plasmas: (1) low density with low energy confinement (L-mode), and (2) high density with high energy confinement (H-mode). To avoid perturbation of the ${ }^{13} \mathrm{C}$ deposited layer by subsequent plasma operations, each ${ }^{13} \mathrm{CH}_{4}$ injection was performed on the last day of an experimental campaign, immediately before the vacuum vessel was vented to air. In each experiment, a series of lower single null (LSN) discharges with almost identical magnetic field configurations (Fig. 1) was carried out: safety factor at $95 \%$ of normalized poloidal flux, $q_{95}=4.2$, plasma current $I_{p}=1.1 \mathrm{MA}$, and magnitude of the toroidal field, $B_{T}=2.0 \mathrm{~T}$. $\mathbf{B}_{\mathbf{T}}$ was in the 'forward' direction, so that the ion $\mathbf{B} \times \nabla B$ vector pointed toward the lower divertor. During the current flattop, the inner and outer strike points were maintained stationary within a tolerance of $1 \mathrm{~cm}$. Prior to injection of ${ }^{13} \mathrm{CH}_{4}$, discharges with divertor $\mathrm{X}$ point sweeps were performed to document the divertor plasma conditions and to determine the amount of methane to be injected using ordinary methane, ${ }^{12} \mathrm{CH}_{4}$. Fig. 2 shows the time evolution of the selected plasma parameters to assess the effect of the ${ }^{13} \mathrm{CH}_{4}$ on the plasma conditions in the two experiments.

\section{A. ${ }^{13} \mathrm{CH}_{4}$ injection into $\mathrm{L}$-mode plasmas}

A low-density L-mode plasma was chosen as the target plasma in the $2003{ }^{13} \mathrm{C}$ injection experiment [Stangeby_JNM03]: $\left\langle n_{e}\right\rangle=2.8 \times 10^{19} \mathrm{~m}^{-3}$, or $\left\langle n_{e}\right\rangle / n_{G W} \sim 0.28$, where $n_{G W}$ is the Greenwald density [Greenwald_NF88]. Plasma heating was predominately ohmic heating with short neutral beam pulses applied to permit charge exchange spectroscopy measurements. Upstream separatrix parameters of $n_{e, s e p} \approx 6 \times 10^{18} \mathrm{~m}^{-3}$ and $T_{e, s e p} \approx 40 \mathrm{eV}$ (thus, moderately collisional SOL, $v_{e, s e p}^{*} \approx 3$ ) measured at the outer midplane lead to an attached outer divertor plasma, with $T_{e, O S P} \approx 20-30 \mathrm{eV}$, and a significantly colder inner divertor plasma, $T_{e, I S P}<5 \mathrm{eV}$. The ion saturation current profile, $I_{s a t}(\mathrm{r})$, measured by Langmuir probes at the inner plate was 
non-zero, and the peak $I_{\text {sat }}$ at the inner plate was $1 / 2$ that at the outer plate (Fig. 3). At the inner target $I_{\text {sat }}(\mathrm{r})$ indicates two peaks, at the inner separatrix and at normalized flux $\Psi_{\mathrm{N}} \sim 1.025$. The physics of the $I_{\text {sat }}$ peak at $\Psi_{\mathrm{N}} \sim 1.025$ remains unresolved, but is possibly related to the transition of the outer strike zone from the divertor floor to the lower divertor baffle. The peak heat flux to the outer plate was 10 times higher than that to the inner plate (Fig. 2). Emission from low-n Balmer lines of deuterium was used to assess the balance of ionization and recombination in the inner divertor, and to derive an estimate for the electron temperature near the target plate. The measured line ratio of $D_{\beta} / D_{\alpha}$ in the vicinity of inner strike point was 0.15 , indicating significant volume recombination with $T_{e}<1.5 \mathrm{eV}$ [Isler_PoP97, McCracken_NF38]. At the inner divertor plasma, the 2-D spatial distributions of emission from singly and doubly ionized carbon showed strong emission near the X-point, and not at the target plate, further corroborating the point that most of the inner divertor plasma temperature is below $5 \mathrm{eV}$ [Fenstermacher_JNM97].

Toroidally symmetric methane injection into the torus was achieved by puffing into the upper outer plenum. The methane was introduced with a fast valve into three tubes spaced 120 deg apart toroidally in the upper pumping plenum, with the cryo pumps disabled. Suitable injection rates were determined prior to the injection of ${ }^{13} \mathrm{CH}_{4}$ using ${ }^{12} \mathrm{CH}_{4}$ and monitoring the core plasma density, radiated power, core carbon content, and divertor recycling. An injection rate of 4.4 Torr $1 / \mathrm{s}\left(1.4 \times 10^{20} \mathrm{CH}_{4}\right.$ molecules/s $)$ resulted in a small, yet measurable increase of the core carbon content $(\sim 30 \%)$ over the $3 \mathrm{~s}$ duration of ${ }^{13} \mathrm{CH}_{4}$ injection, while the plasma density and radiated power remained constant in the core and SOL regions (Fig. 2).

\section{Carbon emission from the plasma crown and inner midplane SOL}

The measured emission distributions from singly and doubly ionized carbon in the crown during the methane injection are poloidally shifted toward the inner SOL, indicating flow of the 
carbon ions in the direction of the inner divertor [Fig. 4(b) and 4(c)]. Methane is used to enhance the emission from the crown, and thus allow reconstruction of the 2-D profiles from the 3-D image data obtained by tangentially viewing cameras. The elongated distributions of CII (514 $\mathrm{nm})$ and CIII (465 nm) light follow the curvature of the flux surfaces in the crown, with their emission profiles peaking radially at the $2.5 \mathrm{~cm}$ and $2 \mathrm{~cm}$ flux surfaces (outer midplane), respectively. Measurements of the electron density and temperature at these flux surfaces near the outer midplane showed $\sim 2-3 \times 10^{18} \mathrm{~m}^{-3}$ and $\sim 10-12 \mathrm{eV}$, respectively, consistent with an ionization mean free path of 3-4 cm for carbon atoms with $1 \mathrm{eV}$ energy resulting from dissociative break-up of $\mathrm{CH}_{4}$ [Stangeby_JNM06]. While the emission peak of CII was clearly in the view of the camera, that of CIII was located poloidally out of the camera view, closer to the inner midplane region. A similar poloidal shift of CII and CIII was observed with the poloidal arrays of the line emission monitors and spectrometer viewing the ceiling of the DIII-D vessel [McLean_JNM05].

Imaging of the emission from the $\mathrm{CH} / \mathrm{CD}$ fragment of the hydrocarbon dissociation chain in identical methane injection experiments, but in reversed toroidal field configuration, was used to estimate the birthplace of singly ionized carbon. The $\mathrm{CH} / \mathrm{CD}$ emission of the $\mathrm{A}-\mathrm{X}$ band (band head at $432 \mathrm{~nm}$ ) peaked in the plasma region shadowed by the upper divertor baffle, more than $20 \mathrm{~cm}$ away from the injection location [Fig. 4(a)]. The fact that the $\mathrm{CH} / \mathrm{CD}$ emission profile followed the curvature of the magnetic field may be indicative of the plasma temperature distribution in the far SOL, but could also relate to the fact that the dissociation of methane to $\mathrm{CH} / \mathrm{CD}$ passes through ionized fragments. Plasma conditions in the crown radially inboard of the upper baffle limiter (far SOL) are unknown because of the lack of diagnostic coverage. Given the low energy needed to dissociate the methane molecule to $\mathrm{CH}, E_{d i s}<1 \mathrm{eV}$, the plasma in the far SOL is likely rarified and cold. This is supported by Langmuir probe measurements of the plasma density and temperature at the flux surface intersecting the tip of the limiter, which yielded $n_{e}<8 \times 10^{17} \mathrm{~m}^{-3}$ and $T_{e}<3 \mathrm{eV}$. Assuming that the far SOL plasma is stagnant, the spatial 
distribution of methane dissociation to neutral carbon is similar in forward and reversed $B_{T}$ configuration, and thus the birthplace of carbon ions is unaffected by the $B_{T}$ field direction.

A maximum velocity of $15 \mathrm{~km} \mathrm{~s}^{-1}$ of singly ionized carbon along the field lines toward the inner divertor can be inferred from the lifetime of this ionization state in the crown $\left(\tau_{\text {ioniz }} \sim 0.1 \mathrm{~ms}\right)$ and the poloidal displacement of the peak in the CII emission with respect to $\mathrm{CH} / \mathrm{CD}$ emission $\left(\Delta s_{p o l} \sim 0.15 \mathrm{~m}\right)$ :

$$
v_{\|}^{\mathrm{C}^{+}}=\frac{B}{B_{\text {pol }}} \Delta s_{\text {pol }} / t_{\text {ioniz }}^{\mathrm{C}^{+} \rightarrow \mathrm{C}^{2+}} .
$$

This estimate would imply that singly ionized carbon reaches supersonic velocities (relative to the carbon sound speed) upon ionization in the SOL, however, it uses the following assumptions, which put the quoted velocity as an upper bound: (1) singly ionized carbon is born at the same poloidal location as the peak $\mathrm{CH} / \mathrm{CD}$ emission, (2) radial transport of singly ionized carbon is comparable to, or faster than ionization from $\mathrm{C}^{+}$to $\mathrm{C}^{2+}\left(\tau_{\perp} \leq \tau_{\text {ioniz }}\right)$, and (3) an ionization time derived from the plasma conditions at the location of the CII emission. In particular the latter assumption may be a significant underestimate, since CII emission of the ${ }^{4} P-{ }^{4} P^{0}$ transition at $514.5 \mathrm{~nm}$ occurs at temperatures considerably higher than the ionization potential of singly ionized carbon $\left(\mathrm{E}_{\text {excit,CII }} \sim \mathrm{E}_{\text {ioniz,C+ } \rightarrow \mathrm{C} 2+}\right)$ [ADAS]. Thus, $\tau_{\text {ioniz }}$ may be as long as $1 \mathrm{~ms}$, and so the inferred $\mathrm{C}^{+}$velocity may be smaller by an order of magnitude.

CII and CIII emission obtained along the inner main SOL above the midplane showed a fourfold increase in intensity during the methane injection (Fig. 5). This would put the peak CIII emission arising from the methane injection in the region bounded by elevation $Z=0.5 \mathrm{~m}$ and $Z=0.8 \mathrm{~m}$. Below the inner midplane, the intrinsic carbon emissions were much brighter, and the increase in the carbon emissions from the injected methane was harder to detect. A two-fold increase of the CIII emission was also measured by a radially viewing chord, that intersected both the inner and outer midplane SOL. Taking both camera and line-integrated measurements 
into account, the increase in the CIII emission observed by the radial chord may be interpreted as an increase in the inner SOL only, and no change in the emission at the outer SOL.

\section{Tile surface analysis}

A total of $1.0 \times 10^{22}$ atoms of ${ }^{13} \mathrm{C}$ were injected into plasma in 22 identical discharges with 5minute between-shot glow discharge cleaning in helium. Data from a residual gas analyzer showed that only $0.5 \%$ of the injected ${ }^{13} \mathrm{C}$ was removed by the glow. After venting the machine a set of 29 tiles was removed from the vessel, most tiles representing a single poloidal crosssection, along with a number of divertor tiles from the toroidally opposite location.

Surface analysis of the plasma-exposed tiles showed a surface concentration of ${ }^{13} \mathrm{C}$ deposition at the inner divertor strike zone more than 100 times higher than at the outer strike zone [Fig. 6(b)] [Wampler_JNM05]. The peak deposition was found one tile radially inboard of the inner strike point $(\sim 20 \mathrm{~cm})$, at the interface of the floor and the 45-degree tilted inner divertor wall. No significant amounts of ${ }^{13} \mathrm{C}$ deposition was measured along the private flux target and in regions outboard of the outer strike point. Two surface analysis techniques were employed, which produced spatially equivalent profiles: nuclear reaction analysis (NRA) using a $2.5 \mathrm{MeV}$ ${ }^{3} \mathrm{He}$ beam, and proton-induced gamma emission (PIGE) with a $1.748 \mathrm{MeV}$ proton beam [Wampler_JNM05, Whyte_ITPA04]. The detection limit of the NRA method is $\sim 2 \times 10^{16}$ atoms $\mathrm{cm}^{-2}$ with a depth resolution corresponding to about $0.6 \mu \mathrm{m}$ of graphite, which is thicker than the region containing deposited ${ }^{13} \mathrm{C}$. PIGE analysis is significantly more sensitive (detection limit $\sim 1 \times 10^{15}$ atoms $\mathrm{cm}^{-2}$ ). Poloidal scans toroidally displaced along the plasma-facing surface on any given tile produced a very similar ${ }^{13} \mathrm{C}$ distribution. Deposition profiles from analysis of tiles from the same poloidal position but at different toroidal angles were almost identical, indicating that the ${ }^{13} \mathrm{C}$ deposition was toroidally symmetric. The integrated ${ }^{13} \mathrm{C}$ deposition along the divertor tile surfaces was found to account for approximately $30 \%$ of the injected ${ }^{13} \mathrm{C}$. 
Outside the divertor the ${ }^{13} \mathrm{C}$ deposition was measured to be one order of magnitude lower than in the divertor [Fig. 6(a)]. The more sensitive PIGE analysis carried out on ceiling tiles adjacent to the injection location showed a surface deposition of $1-3 \times 10^{16}$ atoms $\mathrm{cm}^{-2}$ to a depth of $400 \mathrm{~nm}$, which when integrated around the centerpost and inner upper divertor accounts for about $40 \%$ of the injected ${ }^{13} \mathrm{C}$ [Whyte_ITPA04]. The remaining $30 \%$ has yet to be found. Potential candidates are tile edges along the center column, and the side walls of divertor tiles. In support of this hypothesis, recent studies with the Divertor Materials Evaluation System (DiMES) sample [Wong_JNM98] showed the formation of a deuterium-rich carbon film along a simulated tile gap, reaching a maximum surface density of $6 \times 10^{15} \mathrm{C}$ (D) $\mathrm{cm}^{-2}$ [Krieger_JNM06]. However, preliminary NRA surface analysis for ${ }^{13} \mathrm{C}$ deposited on the side wall of a single tile in the inner divertor [Fig. 6(a): tile \#19, surface facing the floor tile \#20] did not show elevated levels of ${ }^{13} \mathrm{C}$ above the natural background, however, more tiles need to be analyzed for this to be considered conclusive.

\section{B. ${ }^{13} \mathrm{CH}_{4}$ injection into $\mathrm{H}$-mode plasmas}

To mimic the detached divertor conditions anticipated in ITER, trace ${ }^{13} \mathrm{C}$ injection into a series of 17 identical high-density H-mode plasmas and ex-situ tile analysis were performed. Neutral beam heating $(6.5 \mathrm{MW})$ permitted plasma operation at high density, $\left\langle n_{e}\right\rangle=8.0 \times 10^{19} \mathrm{~m}^{-3}$ $\left(\left\langle n_{e}\right\rangle / n_{G W} \sim 0.88\right)$, and with moderate plasma performance (energy confinement: $\mathrm{H}_{89} \sim 1.35$, normalized $\left.\beta_{N} \sim 1.6\right)$. Pedestal parameters of $n_{e, p e d} \approx 7.6 \times 10^{19} \mathrm{~m}^{-3}$ and $T_{e, p e d} \approx 200 \mathrm{eV}$ were obtained. At the separatrix $n_{e, s e p}$ and $T_{e, s e p}$ were measured $\sim 6 \times 10^{19} \mathrm{~m}^{-3}$ and $\sim 75 \mathrm{eV}$,

respectively, resulting in a highly collisional SOL $\left(v_{e, s e p}^{*} \approx 20\right)$. These upstream conditions led to fully detached divertor plasmas in front of both the inner and outer target plate, consistent with low target particle and heat fluxes measured by Langmuir probes and infra-red thermography (Figs. 2 and 3). Edge localized modes, or ELMs, periodically perturbed the SOL at a frequency of $200 \mathrm{~Hz}$. The ELMs were of low amplitude with a relatively long pulse width (50\% duty 
cycle). During the $4 \mathrm{~s}$ heating phase the surface temperature of the inner target plate increased from $325 \mathrm{~K}$ to $332 \mathrm{~K}$, and of outer target plate from $332 \mathrm{~K}$ to $360 \mathrm{~K}$.

Measurements from several diagnostics with time resolution sufficient to resolve the ELMs indicate re-attachment of the inner and outer divertor plasma in response to the ELM perturbation occurring upstream in the pedestal region. In inter-ELM periods the ion currents to the inner and outer divertor targets were greatly reduced in H-mode compared to the L-mode case, indicating much stronger divertor detachment. However, bursts in $I_{\text {sat }}$ occurred during the ELMs that momentarily reached, or even exceeded, the L-mode $I_{\text {sat }}$ levels (Fig. 3). The lineintegrated density through the private flux and outer divertor regions also showed a 30-60\% increase at the peak of the ELM perturbation. Imaging of the CIII emission (465 nm) in the lower divertor with a fast-gated camera at $1 \mathrm{~ms}$ shutter time per $16.7 \mathrm{~ms}$ frame showed the peak emission moving from the X-point region in the inter-ELM period toward the inner and outer targets at the peak of the ELM [Fig. 7(a,b)]. Such strong re-distribution of the CIII emission during an ELM has been previously interpreted as momentary re-attachment of the divertor plasma [Groth_JNM03]. Using the same imaging technique, the $D_{\gamma}$ emission showed an order of magnitude increase in the $D_{\gamma}$ light at the inner plate at the peak of the ELM [Fig. 7(c,d)]. This rise may have been driven by either collisional excitation of deuterium atoms near the divertor plate, or by recombination of ions, when the ionization front reached toward the plate during the ELM. The time evolution of the divertor CI emission $(910 \mathrm{~nm})$ over the ELM cycle was similar to $D_{\gamma}$. Since both collisional excitation and recombination contribute to the production of CI light, this emission depends on how much carbon erosion occurs at the inner target during an ELM (divertor source), and how $C^{+}$ions are transported by the ELM into the divertor plasma (remote source) during an ELM. Unfortunately, spectroscopic measurements of CI line shape did not have sufficient time resolution (100 ms, or 20 ELM cycles) to resolve one process from the other. 
Thomson scattering measurements in the outer divertor leg, on the other hand, showed that the ELM perturbations only reach the ionization front half way between the outer plate and the X-point, and not the target plate [Lisgo_ICSLS06]. 2-D maps of the $n_{e}$ and $T_{e}$ distribution of the private flux region and outer common SOL were obtained during strike points sweeps on the plasma characterization day. The ionization front, with density $8 \times 10^{20} \mathrm{~m}^{-3}$, extended across the outer divertor leg and into the private flux region. Below the ionization front $T_{e}$ remains less than $2 \mathrm{eV}$ throughout the ELM cycle.

Higher densities in $\mathrm{H}$-mode permitted an increase of the ${ }^{13} \mathrm{CH}_{4}$ injection rate $\left(6.0 \times 10^{20}\right.$ ${ }^{13} \mathrm{CH}_{4}$ molecules/s) by a factor of 4.3 over the L-mode case, however, the relative contribution of additional hydrogen $\left(2.4 \times 10^{21} \mathrm{H}\right.$ atoms/s $)$ to the core fueling was significantly smaller than in L-mode, since the core plasma density remained constant during the ${ }^{13} \mathrm{CH}_{4}$ injection (Fig. 2). The upstream SOL density gradually increased over the course of the ${ }^{13} \mathrm{CH}_{4}$ injection, accompanied by an increase of the $D_{\alpha}$ and $D_{\gamma}$ emission in the divertor.

\section{Carbon emission from the plasma crown and inner midplane SOL}

In contrast to the L-mode, imaging of the $\mathrm{CH} / \mathrm{CD}, \mathrm{CII}$, and $\mathrm{CIII}$ emissions in the crown of the plasma during the methane injection into $\mathrm{H}$-mode plasmas does not clearly indicate a poloidal flow of low charge state carbon ions toward the inner divertor (Fig. 8). The SOL plasma conditions at the flux surface limited by the upper outer baffle were significantly hotter and denser in these plasmas than in the L-mode case, $T_{e} \approx 10-15 \mathrm{eV}, n_{e} \approx 6 \times 10^{18} \mathrm{~m}^{-3}$, leading to more rapid dissociation of $\mathrm{CH}_{4}$ and ionization of resulting carbon to higher ionization states. The broad character of the CIII emission at the crown, $(\mathrm{R}, \mathrm{Z})=(1.4 \mathrm{~m}, 1.1 \mathrm{~m})$, as shown in Fig. $7 \mathrm{c}$, is likely to be caused by ELMs, periodically changing the SOL conditions, as the images were integrated over $17 \mathrm{~ms}$ (3-4 ELM periods). The upper divertor is not instrumented with a fastgated, intensified camera that would permit ELM-resolved images. The hydrocarbon/carbon images, as well as Langmuir probe ion current and $D_{\alpha}$ measurements, show strong interaction of 
the SOL plasma with the tip of the upper outer baffle. During an ELM the ion saturation current at the limiter increased by a factor of 3-4, accompanied by an increase in the $D_{\alpha}$ line intensity. The increase of the ion carbon emission in the inner midplane SOL during the methane injection was small, but measurable: CII by $1.5 \mathrm{x}$ and CIII by $2 \mathrm{x}$.

\section{Tile surface analysis}

In detached $\mathrm{H}$-mode a total of $2.2 \times 10^{22}$ atoms of ${ }^{13} \mathrm{C}$ were injected into 17 identical discharges. To maintain reproducible plasma conditions, helium glow discharge cleaning was performed between discharges, which removed less than $1 \%$ of injected ${ }^{13} \mathrm{C}$ from the vacuum vessel. After venting the machine to air, 64 tiles were carefully removed for NRA and PIGE surface analysis. 49 of those tiles represent an entire poloidal sample at one toroidal location, while the remainder was used to assess toroidal symmetry and deposition at specific wall locations, such as limiters.

The two most striking results of the NRA analysis are (1) a similar ${ }^{13} \mathrm{C}$ deposition at the inner divertor in $\mathrm{H}$-mode as in the L-mode, and (2) substantial ${ }^{13} \mathrm{C}$ deposition on surfaces exposed to plasma across the entire the private flux region [Fig. 4(a)] [Wampler_JNM06]. Both NRA and PIGE analyses showed no ${ }^{13} \mathrm{C}$ deposition at the outer strike zone. Assuming toroidal symmetry, which is justified by surface analyses of tiles at different toroidal angles, about $13 \%$ of the injected ${ }^{13} \mathrm{C}$ was deposited at the inner strike zone, and $24 \%$ in the private flux region. Significant amounts of ${ }^{13} \mathrm{C}$ were found by both techniques in the upper divertor near the ${ }^{13} \mathrm{CH}_{4}$ injection location [Fig. 4(b)], which account for $8-10 \%$ of the total injected ${ }^{13} \mathrm{C}$. Hence, in $\mathrm{H}-$ mode we were able to account for about $50 \%$ of the total amount of injected ${ }^{13} \mathrm{C}$. As argued in the L-mode case, PIGE analysis suggests that some part of the injected ${ }^{13} \mathrm{C}$ may be located in low-level deposits along the center post. Ongoing NRA analysis also includes surfaces that were not in direct contact with plasma, e.g., the side walls of tiles. 


\section{DISCUSSION}

The following physics picture emerges from the DIII-D ${ }^{13} \mathrm{C}$ experiments: carbon sputtered in the upper main chamber is transported over the crown into the inner divertor, where it is deposited inboard of the inner strike point (low density L-mode and high density H-mode) and at the private flux wall (high density H-mode). Plasma spectroscopy and imaging have shown that it is unlikely that carbon from the main chamber is transported into the outer divertor, although the experimental evidence is less conclusive in H-mode with ELMs than in L-mode. Previous experiments of erosion and deposition using DiMES showed that, in the divertor, carbon accumulates on surfaces facing a cold and dense plasma, like the private flux walls, while net deposition is significantly lower, or even zero, at the strike point locations [Wampler_JNM01, Whyte_NF01]. Carbon may migrate away from areas of strong plasma-wall interaction into regions shadowed from direct plasma exposure, including tile gaps, but the extent of such migration has yet to be assessed.

The flow of carbon in the main SOL inferred from the camera images in L-mode at the crown is consistent with the hypothesis of entrainment of the carbon ions in a deuterium flow at one half of the SOL deuterium sound speed. Analysis of reciprocating Langmuir probe measurements in the crown of low density, upper single null L-mode plasmas in DIII-D [Boedo_PC06] showed deuteron flow of $M_{\|}=0.5$ in the direction of the inner divertor, where $M_{\|}=\mathrm{v}_{\|} / \mathrm{c}_{\mathrm{s}}\left(D^{+}\right)$and $\mathrm{c}_{\mathrm{s}}\left(D^{+}\right)$is the deuteron sound speed. These results are consistent with reciprocating probe measurements in other fusion devices in Ohmic and L-mode plasmas with single null configurations and the $\mathbf{B} \times \nabla B$ vector pointing into the divertor [Erents_PPCF04, LaBombard_NF04, Asakura_NF04, Gunn_JNM06, Mueller_JNM06]. LaBombard et al. [LaBombard_NF04] showed that the flow field may vary both poloidally and radially. Recent measurements in ASDEX-Upgrade also exhibit similar flows in low power H-mode plasmas [Mueller_JNM06]. For SOL conditions characteristic of the DIII-D ${ }^{13} \mathrm{C}$ L-mode experiment, frictional coupling of the $C^{+}$ions to the deuterium flow is sufficiently strong to accelerate the 
carbon ions to the velocity of the deuterium ions before ionization of carbon to the next charge state $\left(\tau_{\text {Spitzer }}<<\tau_{\text {ioniz }}\right.$, Table 1$)$. Although the velocity for $C^{2+}$ ions cannot be directly inferred from the camera data, frictional coupling of $C^{2+}$ ions to deuterium ions is also strong. Even in high density $\mathrm{H}$-mode, carbon in the SOL rapidly ionizes to charge states higher than $2+$, however, the lifetime of $C^{2+}$ ions is still significantly longer than the collision time between $D^{+}$ and $C^{2+}$ providing a strong drag on the carbon ions (Table 1).

The measured ${ }^{13} \mathrm{C}$ deposition along the divertor surfaces is the result of two phenomena: (1) transport and first deposition of ${ }^{13} \mathrm{C}$ ions and neutrals in the divertor SOL, and (2) migration due to re-erosion of the deposits. Since the ${ }^{13} \mathrm{C}$ deposition profile at the inner divertor plate exhibits in L-mode a similar double-peak feature of the ion current measured, ${ }^{13} \mathrm{C}$ deposition may be entirely due to ion transport in this confinement regime. In H-mode plasma with ELMs, both physical and chemical erosion during the ELM pulse may play a more important role than first deposition of ${ }^{13} \mathrm{C}$ neutrals. Since the deposition of ${ }^{13} \mathrm{C}$ on the divertor target plates is likely to occur in the form of soft films, the actual erosion yields may be higher than yields published for graphite [Davis_JNM97, Roth__NF04], hence less energy is needed to re-erode surface layers formed between ELMs. Modeling of the JET quartz microbalance results with the ERO code showed that enhanced re-erosion of deposited carbon films as high as $8 \%$ was needed to bring the code results in agreement with the measurement [Kirschner_JNM05]. Measurements of molecular carbon sources in JET corroborated the existence of soft hydrocarbon layers in low heat flux areas [Brezinsek_JNM05]. It is therefore conceivable that during ELMs re-erosion of the ${ }^{13} \mathrm{C}$ deposits at the inner divertor leads to migration away from the plasma strike zones, producing the high ${ }^{13} \mathrm{C}$ concentration at the private flux wall inboard of the outer strike point [Fig. 6(b), tiles \#22, 23]. Similarly, migration of ${ }^{13} \mathrm{C}$ deposits from the inner strike zone into the 
corner formed by the $45^{\circ}$ angled tiles and the divertor floor may have also occurred, although data that support such hyypothesis are less evident. The radially outward migration of ${ }^{13} \mathrm{C}$ is stopped at the outer separatrix, since the plasma temperature in the outer divertor plasma would cause immediate dissociation of the ${ }^{13} \mathrm{C}$ hydrocarbon molecules or fragments, and prompt redeposition of ${ }^{13} \mathrm{C}$. This effect is enhanced by the rise in plasma temperature during the ELM. The ELM-pulsed outer divertor plasma acts, in a sense, as a barrier for migrating hydrocarbons, which would explain why the deposition profile is peaked at the private flux wall immediately inboard of the outer strike point.

Transport of ${ }^{13} \mathrm{C}$ along the outer main SOL, and migration following the initial deposition at the outer plate can almost be ruled out, since (1) none of the spectroscopic measurements and imaging indicated significant increase of the carbon emission in the outer SOL during the $\mathrm{CH}_{4}$ injection, and (2) no significant amounts of ${ }^{13} \mathrm{C}$ were found outboard of the outer strike point. If ELMs were responsible for re-erosion at the outer plate, ${ }^{13} \mathrm{C}$ is more likely to migrate radially outward, into the outer pumping plenum and onto the lower outer baffle, which was not measured.

Long-range ${ }^{13} \mathrm{C}$ migration into the gap between tile \#19 and \#20 [Fig. 6(b)] is conceivable, but no systematic surface analyses have been carried out to-date. Preliminary analysis of one side wall of \#19 tile facing tile \#20 did not show significant ${ }^{13} \mathrm{C}$ deposition above the natural background. However, the gap between tiles \#19 and \#20 is an order of magnitude smaller in DIII-D, 2-5 mm, than, for example, the slot to the inner louver of the JET MKIIAP divertor (3-4 $\mathrm{cm}$ ), which significantly reduces the probability of carbon migration into this plasma-shadowed region. 


\section{SIMULATIONS OF THE DIII-D ${ }^{13} \mathrm{C}$ RESULTS USING OEDGE AND UEDGE}

Due to the complexity of the physics involved in the hydrocarbon breakup, and carbon

transport and migration from the ${ }^{13} \mathrm{CH}_{4}$ source to the locations of the ultimate ${ }^{13} \mathrm{C}$ deposition, specific aspects of these physics processes were addressed with plasma simulations using numerical codes. The OEDGE code was used to investigate the penetration physics of $\mathrm{CH}_{4}$ into the plasma crown, carbon transport in the main SOL, and carbon deposition at the divertor target plates due to transport processes only. Using a more first-principle physics model, deuterium flows in the edge and their effect on carbon transport and deposition were examined with the UEDGE code.

\section{A. OEDGE modeling}

The Onion Skin Model EIRENE DIVIMP edge code (OEDGE) [Stangeby_JNM03] was used to model the dissociation of ${ }^{13} \mathrm{CH}_{4}$ in crown of the plasma, and the transport and deposition of ${ }^{13} \mathrm{C}$ for both the L-mode [McLean_JNM05, Elder_JNM05] and H-mode plasmas [Elder_JNM06]. In this modeling approach, combining the 'onion-skin' prescription and the neutral Monte Carlo code EIRENE [Reiter_JNM92], the hydrogen background plasma was iteratively inferred by empirical reconstruction [Lisgo_JNM05] and validation against experimental data. These data typically included calibrated spectroscopic measurements of low-n Balmer lines $\left(D_{\alpha}, D_{\beta}\right.$, and $\left.D_{\gamma}\right)$ in the divertor, the profile of the ion saturation current $\left(I_{s a t}\right)$ at the target, the measured divertor electron density and temperature from Thomson scattering, and the upstream electron density and temperature profiles. This technique can yield reliable reconstruction of the plasma conditions also at low divertor temperatures at which the plasma is detached [Lisgo_JNM05]. Carbon transport was modeled with the Monte Carlo code DIVIMP [Stangeby_NF88] using the reconstructed background plasma, solving the impurity force balance in the parallel field direction [Neuhauser_NF84], and assuming ad-hoc cross-field diffusion (diffusion coefficient $D_{\perp}$ ) and convection $\left(\mathrm{v}_{\text {pinch }}\right)$. Parallel plasma flow of a specified velocity 
can be prescribed on the background plasma, or on the impurity species directly. DIVIMP follows the carbon particle through neutral and ion states until it is deposited on a surface, either as an ion or as a neutral. Though re-erosion and re-deposition of the injected ${ }^{13} \mathrm{C}$ can be included in the calculations, it has not been explored in the simulations described here.

Modeling of transport and dissociation of hydrocarbons in the background plasma provided by OEDGE, with a prescribed parallel carbon ion velocity of 0.4 times the deuterium ion sound speed, was found to produce a good match of radial and poloidal CII and CIII intensity distributions in the crown of a L-mode plasma [McLean_JNM05]. Recently, a hydrocarbon model was developed inside DIVIMP that permits detailed calculations of the methane dissociation chain [McLean_JNM05, Elder_JNM06] using rates provided by Erhardt and Langer [Erhardt_PPPL87]. The database for the methane breakup chain was further updated to include the rates calculated by Janev and Reiter [Janev_PoP02]. These calculations were performed in realistic geometry on an extended grid including the vacuum region outside the onion-skin modeling domain. Upon reaching the OEDGE plasma grid boundary limited by the upper outer baffle, the dissociation and ionization chain was then followed by the code. Carbon ions are transported cross-field, simulated with a spatially constant diffusion coefficient, $D_{\perp}$, and in parallel field direction by a poloidal velocity, $\mathrm{v}_{\text {pol }}$, toward the divertor plates. In order to match the poloidal and radial location of the CII and CIII emission region, as well as incremental increase of the fully stripped carbon density in the core, a $D_{\perp}$ of $0.3 \mathrm{~m}^{2} \mathrm{~s}^{-1}$ and $\mathrm{v}_{p o l}=B_{p o l} / B \times 0.4 \mathrm{c}_{\mathrm{s}}\left(D^{+}\right)$in the direction of the inner divertor were imposed. Here, $B_{p o l} / B$ is the ratio of poloidal to total magnetic field, $\mathrm{c}_{\mathrm{s}}\left(D^{+}\right)$is the sound speed of deuterium ions, $\mathrm{c}_{\mathrm{s}}\left(D^{+}\right)=\sqrt{\left(2 T_{e}\right) / \mathrm{m}_{\mathrm{D}^{+}}}$, assuming $T_{e}=T_{i}$, and $\mathrm{m}_{\mathrm{D}^{+}}$is the deuterium mass. The assumption on $\mathrm{v}_{p o l}$ yields a parallel $C^{+}$ion velocity of $12 \mathrm{~km} \mathrm{~s}^{-1}$ at the $2.5 \mathrm{~cm}$ flux surface, which is consistent with the velocity inferred from the image data (Section II.A). A poloidally constant velocity field was imposed, spanning the region from the outer to the inner divertor X-point. 
Enhancing the radial transport of the carbon ions, by either moving the $C^{+}$source closer to the separatrix or adding a particle pinch, was required to bring the simulated ${ }^{13} \mathrm{C}$ deposition in the inner divertor in agreement with the surface analysis results [Elder_JNM05, Elder_JNM06]. Using the same transport coefficients that matched the CII and CIII intensity distributions in the plasma crown, together with an upstream ${ }^{13} \mathrm{C}^{+}$source located about 3-6 cm radially outboard of the separatrix, the radial location of the peak in the ${ }^{13} \mathrm{C}$ deposition at the inner divertor was matched. The same result was achieved by imposing a radially inward-going pinch on the carbon ions in the inner SOL of the order 10-20 m s$~^{-1}$, although a theoretical explanation for such pinch has yet to be demonstrated. In the L-mode simulations ${ }^{13} \mathrm{C}$ is dominantly deposited as ions as the imposed SOL flow almost reaches the inner divertor plates. In the H-mode simulations ${ }^{13} \mathrm{C}$ ions recombine before reaching the plate and deposit as neutrals at the inner plate because of the low plasma temperature in the inner divertor leg.

In $\mathrm{H}$-mode the simulated ${ }^{13} \mathrm{C}$ deposition is highly sensitive to the assumptions on how ELMs affect the spatial extent of the carbon flow field in the inner divertor [Elder_JNM06]. Detailed OEDGE modeling shows that the measured ${ }^{13} \mathrm{C}$ deposition profile, including the private flux region, can be reasonably matched by entirely ignoring the effect of ELMs and using a single set of transport coefficients: $\mathrm{v}_{p o l}=B_{p o l} / B \times 0.3 c_{s}\left(D^{+}\right)$, imposed in the SOL above the x-point only, and $\mathrm{v}_{\text {pinch }}=10 \mathrm{~ms}^{-1}$. In contrast to the L-mode case, deposition in the private flux occurs because of the stronger detachment of the inner divertor plasma in $\mathrm{H}$-mode, allowing ions to be transported into the private flux region before they recombine and deposit. On the other hand, the combination of inter-ELM and intra-ELM transport affecting the carbon ions also reproduces the measured ${ }^{13} \mathrm{C}$ deposition profile. As described above, inter-ELM parallel and radial transport produces strong deposition at the private flux wall. Imposing enhanced carbon ion transport during the ELMing phase, by extending the flow field to the inner plate, results in ${ }^{13} \mathrm{C}$ deposition mainly at the inner target plate, away from the inner strike point. Hence, either hypothesis, i.e., ELM-independent or ELM-dependent carbon transport, can explain the observed, dual-peak ${ }^{13} \mathrm{C}$ 
deposition in the lower divertor. The effect of ${ }^{13} \mathrm{C}$ re-erosion due to ELMs, and its concomitant migration away from the inner strike point region have not yet been tested. Future OEDGE analysis will also investigate the effect of the periodically changing background plasma conditions on the resulting ${ }^{13} \mathrm{C}$ deposition.

\section{B. UEDGE modeling}

Detailed studies of deuterium and carbon flows in the SOL were carried out using the fluid edge code UEDGE [Rognlien_JNM92]. UEDGE is a multi-species code that self-consistently calculates plasma solutions for hydrogenic and impurity species on a 2-D grid, typically spanning the core and SOL regions between normalized poloidal flux, $\Psi_{N}, 0.94$ and 1.15. It uses a classical transport description in the parallel $\mathrm{B}$ direction, including the ion $\mathbf{B} \times \nabla B$ and $\mathbf{E} \times \mathbf{B}$ particle drifts [Rognlien_JNM99], and an ad-hoc radial transport model based on diffusion and convection (expressed by $D_{\perp}$ and $\mathrm{v}_{\text {pinch }}$, respectively). Flux limiters are used on the parallel ion and electron heat transport to account for kinetic effects in regions with large parallel gradients. Conductive radial heat transport is expressed by the thermal diffusivities $\chi_{e}$ and $\chi_{i}$ for the electrons and ions, respectively. The radial transport coefficients are set by matching the simulated electron density and temperature profiles in the core and main SOL at the outer midplane to the measured profiles. Hydrogenic atoms may be treated as a fluid species including parallel inertia and neutral-neutral collisions (inertial model [Wising_CPP96]). A common temperature is typically adopted for both the ions and neutrals assuming that charge exchange processes rapidly produce an energetic neutral population. Impurities are modeled as additional fluid species of all ionization states, including the neutral state, applying the same classical transport equations as for the hydrogen species in the parallel B field direction, and an ad-hoc diffusive-convective model in the radial B field direction. The equations for particle continuity, momentum, and electron and ion energy are solved self-consistently within the computational domain, with appropriate conditions at the domain boundaries. 
UEDGE plasma simulations using a simple diffusive radial transport model were previously validated against a large ensemble of experimental data showing that carbon production at divertor plates and the wall can reproduce multiple measurements in the divertor and main SOL without invoking enhanced main chamber recycling [Groth_EPS05]. The modeling predicted that the inner divertor plasma at the target plate was of the order $1 \mathrm{eV}$, consistent with the experiment. However, one of the deficiencies of these modeling cases was that they did not reproduce the measured SOL flow in the direction of the inner divertor.

The effect of the inner divertor plasma conditions on deuterium flow and carbon transport in the main SOL was extensively studied with UEDGE for a plasma similar to the ${ }^{13} \mathrm{C}$ L-mode experiment: low density, lower single null L-mode with the inner strike point at the center post [Stangeby_JNM03]. Based on these simulations further numerical investigations were carried out to elucidate the physics that drive SOL flows. Here, a diffusive model with spatially constant transport coefficients was used to describe the radial particle and heat transport: $D_{\perp}=0.2 \mathrm{~m}^{2} / \mathrm{s}$, $\chi_{e}=\chi_{i}=0.8 \mathrm{~m}^{2} / \mathrm{s}$. At the UEDGE outer wall ( $\Psi_{N}=1.14$; representing the main chamber wall) a gradient scale length of $5 \mathrm{~cm}$ for plasma density and temperature was imposed. The target plates were assumed to be saturated, hence both deuterium neutrals and ions striking the plates were returned into the domain as neutrals with an isotropic angular distribution. Along the outer wall and the private flux region deuterium ions were recycled, and 5\% pumping along the outer wall was imposed on deuterium neutrals.

In the UEDGE simulations presented here intrinsic carbon $\left({ }^{12} \mathrm{C}\right)$ was introduced into the plasma by sputtering at the divertor plates and walls, and extrinsic carbon $\left({ }^{13} \mathrm{C}\right)$ by injection from the outer wall at the crown of the plasma. Physical and chemical erosion at the plates, and chemical erosion at the outer wall were modeled using yields provided by Eckstein et al. [Eckstein_IPP93] for physical sputtering, and Davis et al. [Davis_JNM97] for chemical sputtering. A temperature of $300 \mathrm{~K}$ was assumed for both the plates and the outer wall as indicated experimentally. Upon ionization, the parallel velocity of the carbon ions was calculated 
using a force balance model [Neuhauser_NF84], while carbon ion cross-field transport was described by the same diffusive-convective model as the hydrogen ions. Carbon neutrals were recycled at the target plates and outer wall to simulate, in part, the high recycling coefficient of saturated hydrocarbons [Jacob_JNM05], while for the same boundary regions carbon ions are pumped. At the core boundary the inward-going flux of carbon ions was balanced by an equal outward-going flux. Since in its current version UEDGE does not handle the dissociative breakup of hydrocarbon molecules, ${ }^{13} \mathrm{C}$ injection was simulated by introducing $6 \times 10^{17}{ }^{13} \mathrm{C}$ atoms/s at the outer computational boundary near the plasma crown, and the recycling, transport, and deposition of the injected carbon was modeled like the intrinsic carbon by introducing seven additional fluid species to accommodate ${ }^{13} \mathrm{C}$ neutrals and ions. This is only $0.1 \%$ of a total carbon source of $6 \times 10^{20}{ }^{12} \mathrm{C}$ atoms/s from physical and chemical sputtering. For simplicity the ${ }^{13} \mathrm{C}$ neutral temperature was taken to be the same as the local ion temperature.

The effect of the degree of detachment of the inner divertor plasma on the main chamber SOL flow is contrasted in two UEDGE simulations, which show that the deuteron flow in SOL at the crown is in the direction of the outer divertor target for a detached inner divertor leg, but reverses its direction in the region $\sim 1-4 \mathrm{~cm}$ radially outboard of the separatrix when the inner divertor is attached (Fig. 9). Previous UEDGE studies showed that the degree of detachment strongly depends on the assumptions of the wall conditions at the inner divertor plate and adjacent wall. Increasing the wall pumping at the inner plate of a previously detached inner divertor plasma can lead to an increase of the plasma temperature from $1 \mathrm{eV}$ to $3 \mathrm{eV}$, and thus the ionization front to move from the X-point region toward the inner plate. A similar effect may be obtained by turning off the $\mathbf{E} \times \mathbf{B}$ drifts in the simulations. In raising the plasma temperature at the inner plate from $1 \mathrm{eV}$ to $3 \mathrm{eV}$, the parallel plasma pressure gradient between the outer midplane region and the inner divertor above the ionization front significantly steepens, which provides the drive for the parallel flow in the "far-separatrix" SOL region. The simulations show that, at the plasma crown, the deuterons can reach velocities of $M_{\|}=0.2$ in the direction of the 
inner plate when the inner divertor is attached. The flow velocity decreases toward the separatrix, and even changes sign, because of plasma pressure imbalance between the strike point regions and the upstream SOL (flow reversal [Krasheninnikov_NF92]). The stagnation point of the flow in the main SOL depends on the details of the pressure distribution in the divertor and main SOL, assumptions on radial transport near the outer midplane (convective transport due to intermittency [Pigarov_PoP02] and ballooning-type radial transport [Coster_IAEA04]), and the inclusion of ion $\mathbf{B} \times \nabla B$ and $\mathbf{E} \times \mathbf{B}$ drift effects in the simulations. The UEDGE simulations indicate that ion $\mathbf{B} \times \nabla B$ drifts can drive flows in the inner and outer main SOL from the X-point region to the top, by transporting particles into the core plasma near the crown, and out of the core near the X-point. This flow pattern reverses when the toroidal field is reversed.

At the plasma crown frictional coupling of the carbon ions and the deuterons is sufficiently strong to entrain carbon in the direction of the deuterium flow. The UEDGE simulations show that the CIII emission from the injected ${ }^{13} \mathrm{C}$ may extend in either poloidal direction depending on how strongly the inner leg is detached [Fig. 10(a) and 10(c)]. In attaching the inner divertor, and thus forcing the flow towards the inner target region, the simulated profiles of the carbon emission in the inner divertor plasma [CIII: Fig. 10(b) and 10(d)]] do not match the experimental distribution profiles. For an attached inner divertor plasma, ${ }^{13} \mathrm{C}$ is transported along with the deuterons toward the entrance to the inner divertor. The flow toward the inner plate slows down in the inner divertor plasma primarily due the ion temperature gradient $\left(\nabla T_{i}\right)$ force acting in the direction away from the plate. Depending on the magnitude of the $\nabla T_{i}$ force high charge state carbon ions may be stagnated in the midplane SOL region, and subsequently lost radially to the adjacent wall. Preliminary UEDGE simulations show that reducing the strength of the $\nabla T_{i}$ force in the simulations leads to larger carbon flows into the divertor and less deposition in the main chamber.

The UEDGE simulations predict that the ${ }^{13} \mathrm{C}$ deposition in the divertor also strongly correlates with the degree of detachment of the inner divertor plasma (Table 2). In the case of the 
attached inner divertor plasma, the ratio of ${ }^{13} \mathrm{C}$ deposition at the inner plate over the outer plate is 60:1, while for the detached inner divertor plasma, it is $1: 600$ ! In both cases ${ }^{13} \mathrm{C}$ deposition occurs in the far SOL due to low charge state ions, and the profiles peaks at the grid boundary representing the outer wall. Deposition of higher charge state carbon ions as a consequence of the $\nabla T_{i}$. There is no ${ }^{13} \mathrm{C}$ deposition at the private flux wall. Deposition of ${ }^{13} \mathrm{C}$ in the main chamber constituting about $\sim 40 \%$ of the injected ${ }^{13} \mathrm{C}$ arises from radially diffusion of higher charge state carbon ions trapped at the inner and outer midplane SOL region.

\section{SUMMARY}

Injection of ${ }^{13} \mathrm{CH}_{4}$ into the main SOL of low density L-mode and high-density H-mode plasmas was carried out in DIII-D to elucidate the transport and deposition of carbon sputtered from the main chamber wall. Spectroscopic measurements and plasma imaging near the methane injection location showed that carbon is likely to be entrained by friction in the background plasma flow toward the inner divertor. The highest concentration of ${ }^{13} \mathrm{C}$ deposits in the divertor was measured along surfaces exposed to detached divertor plasmas of temperature less than $2 \mathrm{eV}$ : inboard of the inner strike zone in L-mode and H-mode, and across the private flux region in H-mode. Ex-situ surface analysis showed that in both confinement regimes $30-40 \%$ of the injected ${ }^{13} \mathrm{C}$ is deposited in the divertor, while about $10 \%$ was found in the upper divertor near the injection location. The remaining ${ }^{13} \mathrm{C}$ is assumed to be deposited at levels just above the natural background on plasma-facing surfaces and side walls of tiles along the centerpost and inner divertor.

The measured deposition of ${ }^{13} \mathrm{C}$ on the plasma-facing surfaces is likely to be determined by plasma transport in the SOL and short-range migration. Chemical erosion and sputtering due to ELMs in $\mathrm{H}$-mode, at the strike zones may lead to accumulation of ${ }^{13} \mathrm{C}$ deposits in regions of low plasma exposure. Long-range ${ }^{13} \mathrm{C}$ migration has yet not been assessed, but it is conceivable that migration continues into plasma shadowed regions past tile gaps. This hypothesis is consistent 
with the JET quartz mircobalance results for horizontal divertor plasma configurations, which explained tritium accumulation in the JET inner louver due to carbon co-deposition.

Extensive modeling using the OEDGE and UEDGE codes corroborates the experimental findings that frictional coupling of the carbon ions to the deuteron flow in the SOL is responsible for carbon transport from the main chamber to the divertor. Imposed parallel transport toward the inner divertor and radial transport of carbon ions toward the separatrix were required with OEDGE to bring the plasma simulations in agreement with the measurements. The measured ${ }^{13} \mathrm{C}$ deposition profile at the inner target plate may be matched by first deposition of ${ }^{13} \mathrm{C}$ ions and neutrals, but the effect of re-erosion of ${ }^{13} \mathrm{C}$ deposits has yet to be explored. The UEDGE simulations predict that the direction and magnitude of deuterium SOL flow are dependent on the degree of detachment of the inner divertor plasma. The measured SOL flows and ${ }^{13} \mathrm{C}$ deposition in the divertor can be obtained in the simulations by setting the inner plate boundary conditions to yield an attached inner divertor plasma. Measurements in the inner divertor plasma are, however, indicative of a detached plasma in front of the inner plate.

${ }^{13} \mathrm{C}$ injection studies have yet not elucidated the primary location of the intrinsic carbon source. While results from ${ }^{13} \mathrm{C}$ injection experiments in JET [Coad_NF06] and DIII-D showed that carbon released from the upper main chamber is deposited at the inner divertor, ${ }^{13} \mathrm{C}$ injection into outer divertor SOL in JET [Rubel_EPS05] and JT60-U [Ishimoto_ ICFRM05] also produced deposition at the inner target. These experiments further corroborate that SOL flows and divertor detachment play an important role in where carbon is ultimately deposited.

\section{ACKNOWLEDGMENTS}

This work was performed under the auspices of the U.S. Department of Energy by the University of California Lawrence Livermore National Laboratory under W-7405-ENG-48, DEFG02-04ER54758, DE-FC02-04ER54698, DE-AC04-94AL85000, DE-FG02-04ER54235 and 
supported by the Collaborative Research Opportunities Grant from the Natural Sciences and Engineering Research Council of Canada. The authors would like to thank Drs. S. Brezinsek and R.C. Isler for discussions concerning spectroscopic measurements of hydrocarbons and carbon, and Drs. A. Yu. Pigarov and S.I. Krasheninnikov for discussions regarding UEDGE modeling with convective radial transport. 


\section{REFERENCES}

[ADAS] http://adas.phys.strath.ac.uk

[Allen_JNM05] S.L. Allen, W.R. Wampler, A.G. McLean, D.G. Whyte, W.P. West et al. 2005 J. Nucl. Mater. 337-339 30.

[Andrew_FED99] P. Andrew, P.D. Brennan, J.P. Coad, J. Ehrenberg, M. Gadeberg et al. 1999 Fusion Eng. Des. 43233.

[Asakura_NF04] N. Asakura, H. Takenaga, S. Sakurai, G.D. Porter, T.D. Rognlien et al. Nucl. Fusion 44503.

[Boedo_PC06] J.A. Boedo 2006 Private communication.

[Brezinsek_JNM05] S. Brezinsek, A. Pospieszczyk, M.F. Stamp, A. Meigs, A. Kirschner et al. 2005 J. Nucl. Mater. 337-339 1058.

[Brooks_JNM03] J.N. Brooks, A. Kirchner, D.G. Whyte, D.N. Ruzic. and D.A. Altman 2003 J. Nucl. Mater. 313-316 424.

[Brooks_RSI92] N.H. Brooks, A. Howald, K. Klepper, and W.P. West, 1992 Rev. Sci. Instrum. 635167.

[Carlstrom_RSI92] T.N. Carlstrom et al. 1992 Rev. Sci. Instrum. 634901.

[Carlstrom_RSI97] T.N. Carlstrom, C.L. Hsieh, R. Stockdale, D.G. Nilson, and D.N. Hill 1997 Rev. Sci. Instrum. 701195.

[Coad_NF06] J.P. Coad, J. Likonen, M. Rubel, E. Vainonen-Ahlgren, D.E. Hole et al 2006 Nucl. Fusion 46350. 
[Colchin_RSI03] R.J. Colchin, D.L. Hillis, R. Maingi, C.C. Klepper, and N.H. Brooks et al. 2003 Rev. Sci. Instrum. 742068.

[Davis_JNM97] J.W. Davis and A. A. Haasz 1997 J. Nucl. Mater. 241-243 37.

[Eckstein_IPP93] Eckstein, W. 1993 IPP Report 9/82 Max-Planck-Institute für Plasmaphysik Garching, Germany

[Elder_JNM05] J.D. Elder, P.C. Stangeby, D.G. Whyte, S.L. Allen, A.G. McLean et al. 2005 J. Nucl. Mat. 337-339 79.

[Elder_JNM06] J.D. Elder, A.G. McLean, P.C. Stangeby, S.L. Allen, J.A. Boedo et al. 2006 J. Nucl. Mat. in press.

[Erents_PPCF04] S.K. Erents, R.A. Pitts, W. Fundamenski, J.P. Gunn, and G.F. Matthews Plasma Phys. Control. Fusion 461757.

[Erhardt_PPPL87] A.B. Erhardt and W.D. Langer "Collisional processes of hydrocarbons in hydrogen plasmas", PPPL-2477, September 1987.

[Federici_NF01] G. Federici, C.H. Skinner, J.N. Brooks, J.P. Coad, C. Grisolia et al. 2001 Nucl. Fusion 411967.

[Fenstermacher_JNM97] M.E. Fenstermacher, R. D. Wood, S. L. Allen, N. H. Brooks, D. A. Buchenauer et al 1997 J. Nucl. Mat. 241-243 666.

[Fenstermacher_RSI97] M.E. Fenstermacher, W. H. Meyer, R. D. Wood, D. G. Nilson, R. Ellis et al. 1997 Rev. Sci. Instrum. 70974.

[Greenwald_NF88] M. Greenwald, J.L Terry, S.M. Wolfe, S. Ejima, M.G. Bell et al. 1988 Nucl. Fusion 282199. 
[Groth_EPS05] M. Groth, G.D. Porter,_.D._ray,_·_._rooks,_._. Fenstermacher et al. 2005 Proc. $32^{\text {nd }}$ EPS Conf. on Plasma Physics (Tarragona, Spain, 2005) (ECA 29C) P4.015

[Groth_JNM03] M. Groth, M. E. Fenstermacher, J. A. Boedo, N. H. Brooks, D. S. Gray et al. 2003 J. Nucl. Mat. 313-316 1071.

[Groth_RSI03] N. Groth, M. E. Fenstermacher, C. J. Lasnier, R. Hernandez, J. M. Moller et al. 2003 Rev. Sci. Instrum. 742064.

[Gunn_JNM06] J.P. Gunn et al 2006 J. Nucl. Mat. in press.

[Ishimito_ICFRM05] Y. Ishimoto, Y. Gotoh, K. Masaki, N. Miya, K. Tsuzuki et al. 2005 Proc. $12^{\text {th }}$ International Conference in Fusion Reactor Materials (ICRFM-12), December 4-9, 2006, Santa Barbara, USA

[Isler_PoP06] R.C. Isler, N.H. Brooks, A.G. McLean, and W.P. West 2006 submitted to Phys. Plasmas

[Isler_PoP97] R.C. Isler, G. R. McKee, N. H. Brooks, W. P. West, M. E. Fenstermacher et al. 1997 Phys. Plasmas 42989.

[Jacob_JNM05] W. Jacob 2005 J. Nucl. Mat. 337-339 839.

[Janev_PoP02] R.K. Janev and D. Reiter 2002 Phys. Plasma 94071.

[Keilhacker_NF99] M. Keilhacker, A. Gibson, C. Gormezano and P.H. Rebut 1999 Nucl. Fusion 39209.

[Kirschner_JNM05] A. Kirschner, V. Philipps, D.P. Coster, S.K. Erents, H.G. Esser et al. 2005 J. Nucl. Mat. 337-339 17.

[Krasheninnikov_NF92] S.I. Krasheninnikov 1992 Nucl. Fusion 321927. 
[Krieger_PSI06] K. Krieger, W. Jacob, D.L. Rudakov, R. Bastasz, G. Federici et al. 2006 J. Nucl. Mat. in press.

[LaBombard_NF04] B. LaBombard, J.E. Rice, A.E. Hubbard, J.W. Hughes, M. Greenwald et al. Nucl. Fusion 441047.

[Lao_NF85] L.L. Lao, H. St.John, R.D. Stambaugh, A.G. Kellman, and W. Pfeiffer 1985 Nucl. Fusion 251611.

[Lasnier_NF98] C.J. Lasnier, D.N. Hill, T.W. Petrie, A.W. Leonard, T.E. Evans et al. Nucl. Fusion 381225.

[Lipschultz_PPCF05] B. Lipschultz, D.G. Whyte, and B. LaBombard 2005 Plasma Phys. Control. Fusion 471559.

[Lisgo_ICSLS06] Lisgo, S., Brooks, N.H., Oks, E., Groth, M., Leonard, A.W. et al. 2006 Proc. $18^{\text {th }}$ International Conference on Spectral Line Shapes, June 4-9, 2006, Auburn, USA

[Lisgo_JNM05] S. Lisgo, P.C. Stangeby, J.D. Elder, J.A. Boedo, B.D. Bray et al. 2005 J. Nucl. Mat. 337-339 139.

[Luxon_NF02] J.L. Luxon 2002 Nucl. Fusion 42614.

[Matthew_JNM05] G.F. Matthews 2005 J. Nucl. Mater. 337-339 1.

[McCracken_NF98] M.G. McCracken, M.F. Stamp, R.D. Monk, A.G. Meigs, J. Lingertat et al. 1998 Nucl. Fusion 38619.

[McLean_JNM05] A.G. McLean, J.D. Elder, P.C. Stangeby, S.L. Allen, J.A. Boedo et al. 2005 J. Nucl. Mat. 337-339 124. 
[Mueller_JNM06] H.-W. Mueller, V. Bobkov, A. Herrmann, M. Maraschek, J. Neuhauser et al. 2006 J. Nucl. Mat. in press.

[Neuhauser_NF84] J. Neuhauser, W. Schneider, R Wunderlich and K. Lackner 1984 Nucl. Fusion 2439.

[Pigarov_PoP02] A. Yu. Pigarov, S.I. Krasheninnikov, T.D. Rognlien, M.J. Schaffer, and W.P. West 2002 Phys. Plasma 91287.

[Reiter_JNM92] D. Reiter, et al. 1992 J. Nucl. Mater. 196-198 80.

[Rognlien_JNM92] T.D. Rognlien, et al. 1992 J. Nucl. Mater. 196-198 347.

[Rognlien_JNM99] T.D. Rognlien, G.D. Porter and D.D. Rytov 1999 J. Nucl. Mater. 266-269 654.

[Roth_NF04] J. Roth, R. Preuss, W. Bohmeyer, S. Brezinsek, A. Cambe et al. 2004 Nucl. Fusion 44 L21.

[Rubel_EPS05] M.J. Rubel, J.P. Coad, J. Likonen, G.F. Matthews, D. Hole et al. 2005 Proc. $32^{\text {nd }}$ EPS Conf. on Plasma Physics (Tarragona, Spain, 2005) (ECA 29C) P2.004

[Rudakov_NF05] D.L. Rudakov, J.A. Boedo, R.A. Moyer, P.C. Stangeby, J.G. Watkins et al. 2005 Nucl. Fusion 451589.

[Spitzer_PFIG62] L. Spitzer 1962 Physics of Fully Ionized Gases 2 ${ }^{\text {nd }}$ Ed. New York Wiley 120.

[Stangeby_JNM03] P.C. Stangeby, J. D. Elder, J. A. Boedo, B. Bray, N. H. Brooks et al. 2003 J. Nucl. Mat. 313-316 883.

[Stangeby_NF88] P.C. Stangeby, C. Farrell, and S. Hoskins 1988 Nucl. Fusion 281945. 
[Vainonen-Ahlgren_JNM05] E. Vainonen-Ahlgren, J. Likonen, T. Renvall, V. Rohde, R. Neu et al. 2005 J. Nucl. Mat. 337-339 55.

[Wampler_JNM01] W.R. Wampler, D. G. Whyte, C. P. C. Wong and W. P. West 2001 J. Nucl. Mater. 290-293 346.

[Wampler_JNM05] W.R. Wampler, S.L. Allen, A.G. McLean and W.P. West 2005 J. Nucl. Mater. 337-339 134.

[Wampler_JNM06] W.R. Wampler, A.G. McLean, S.L. Allen, N.H. Brooks, J.D. Elder et al. 2006 J. Nucl. Mater. in press

[Watkins_JNM97] J.G. Watkins,. R. A. Moyer, J. W. Cuthbertson, D. A. Buchenauer, T. N. Carlstrom et al. 1997 J. Nucl. Mater. 241-243 645.

[Watkins_RSI92] J.G. Watkins, J. Salmonson, R. Moyer, R. Doerner, R. Lehmer et al. 1992 Rev. Sci. Instrum. 634728.

[Whyte_ITPA04] D.G. Whyte, G. Wright, S. Harrison, J. Kulpin, C. Chrobak, et al. 2004 presented at the $5^{\text {th }}$ meeting of the International Tokamak Physics Activity (ITPA), Divertor and Scrape-off Layer Physics Group, November 8-11, 2004, Lisbon, Portugal

[Whyte_JNM01] D.G. Whyte, et al. 2001 J. Nucl. Mater. 290-293 356.

[Whyte_NF01] D.G. Whyte, W.P. West, C.P.C. Wong, R. Bastasz, J.N. Brooks et al. Nucl. Fusion 411243.

[Whyte_PPCF05] D.G. Whyte, B L Lipschultz, P C Stangeby, J Boedo, D L Rudakov, et al. 2005 Plasma Phys. Control. Fusion 471579.

[Wienhold_JNM01] P. Wienhold, H. G. Esser, D. Hildebrandt, A. Kirschner, M. Mayer et al. 2001 J. Nucl. Mater. 290-293 362. 
[Wising_CPP96] F. Wising, D. A. Knoll, S. I. Krasheninnikov, T. D. Rognlien, D. J. Sigmar et al. 1996 Contrib. Plasma Phys. 36136.

[Wong_JNM98] C.P.C. Wong, D. G. Whyte, R. J. Bastasz, J. Brooks, W. P. West et al. 1998 J. Nucl. Mater. 258-263 433. 
Table 1. Comparison of the Spitzer times for collisions of deuterium with carbon ions [Spitzer_PFIG62] to the transit time of carbon ions in a singly and doubly ionized state.

\begin{tabular}{lll}
\hline & L-mode & H-mode \\
\hline $\mathrm{n}_{\mathrm{e}}\left(10^{18} \mathrm{~m}^{-3}\right)$ & 4 & 7 \\
$\mathrm{~T}_{\mathrm{e}}(\mathrm{eV})$ & 5 & 20 \\
$\tau_{\text {Spitzer }}(\mathrm{s})$ & $\mathrm{D}^{+} \rightarrow \mathrm{C}^{+}: 2 \times 10^{-5}$ & $\mathrm{D}^{+} \rightarrow \mathrm{C}^{+}: 3 \times 10^{-5}$ \\
$\tau_{\text {ionize }}(\mathrm{s})$ & $\mathrm{C}^{+} \rightarrow \mathrm{C}^{2+}: 7 \times 10^{-4}$ & $\mathrm{C}^{2+} \rightarrow \mathrm{C}^{3+}: 2 \times 10^{-4}$ \\
$\mathrm{v}_{\| \mid}\left(\mathrm{D}^{+}\right)=0.5 \mathrm{c}_{\mathrm{S}}\left(\mathrm{D}^{+}\right)\left(10^{4} \mathrm{~m} \mathrm{~s}^{-1}\right)$ & 1.1 & 2.2 \\
$\mathrm{v}_{\|}(\mathrm{C})\left(10^{4} \mathrm{~m} \mathrm{~s}^{-1}\right)$ & $\mathrm{C}^{+}: \sim 1.5$ & \\
\hline
\end{tabular}


Table 2. UEDGE simulations of ${ }^{13} \mathrm{C}$ deposition calculated for a low density L-mode plasma with intrinsic ${ }^{12} \mathrm{C}$ and an additional ${ }^{13} \mathrm{C}$ source of $6.3 \times 10^{17}{ }^{13} \mathrm{C} / \mathrm{s}$ at the crown. Two cases with an attached $\left(\mathrm{T}_{\mathrm{e}, \mathrm{ISP}}=3 \mathrm{eV}\right)$ and detached $\left(\mathrm{T}_{\mathrm{e}, \mathrm{ISP}}=1 \mathrm{eV}\right)$ inner divertor plasma are compared.

\begin{tabular}{lll}
\hline Erosion/deposition $\left({ }^{13} \mathrm{C} / \mathrm{s}\right)$ & $\mathrm{T}_{\mathrm{e}, \mathrm{ISP}}=3 \mathrm{eV}$ & $\mathrm{T}_{\mathrm{e}, \mathrm{ISP}}=1 \mathrm{eV}$ \\
Inner plate & $4.5 \times 10^{17}$ & $6.3 \times 10^{17}$ \\
Outer plate & $7.6 \times 10^{17}$ & $3.5 \times 10^{17}$ \\
Main wall (minus ${ }^{13} \mathrm{C}$ puff) & $1.7 \times 10^{17}$ & $2.7 \times 10^{17}$ \\
PF wall & 0.0 & 0.0 \\
\hline
\end{tabular}




\section{Figure captions}

Fig. 1. The DIII-D vacuum vessel with reconstructions of the poloidal magnetic field of the Lmode (black) and H-mode (red) plasmas using the EFIT code [Lao_NF85]. The separatrix, and the outer midplane $2 \mathrm{~cm}, 4 \mathrm{~cm}$, and $6 \mathrm{~cm}$ poloidal flux surfaces in the SOL are shown for the two confinement regimes. In the main chamber the SOL was limited on the toroidally symmetric upper outer baffle in L-mode and H-mode at the $6 \mathrm{~cm}$ and $5 \mathrm{~cm}$ flux surfaces, respectively. Methane was injected through the plenum of the upper outer cryo pump, providing toroidally symmetric flow through the plenum gap.

Fig. 2. Time evolution of plasma parameters in L-mode (black) and H-mode (red) plasmas: a) plasma current, b) neutral beam power, c) ${ }^{13} \mathrm{CH}_{4}$ injection, d) pedestal density, e) total radiated power, peak heat flux to the inner (f) and outer (g) divertor plates, and h) $\mathrm{C}^{6+}$ density measured at $\rho \sim 0.9$.

Fig. 3. Profiles of ion saturation current along the inner (a) and outer (b) strike zones obtained during strike point sweeps as a function of the normalized flux, $\Psi_{\mathrm{N}}$. The black circles denote Lmode data, the red squares represent measurements in H-mode. The vertical line indicates the position of the inner and outer separatrix at $\Psi_{\mathrm{N}}=1.0$. 
Fig. 4. Tomographic reconstruction of the emission from (a) $\mathrm{CH} / \mathrm{CD}$ (432 nm), (b) CII (515 $\mathrm{nm}$ ), and (c) CIII (465 $\mathrm{nm}$ ) in the plasma crown during $\mathrm{CH}_{4}$ injection into L-mode. A magnetic configuration with the $3 \mathrm{~cm}$ flux surface limited by the upper outer limiter was chosen to permit better coverage of the crown with the tangential cameras. The $\mathrm{CH} / \mathrm{CD}$ emission profile was obtained in a low density L-mode plasma in reversed BT configuration (ion $\mathbf{B} \times \nabla B$ up). The thick red lines represent the separatrix; the other red lines are poloidal flux contours in the SOL with $1 \mathrm{~cm}$ separation at the outer midplane. CII emission along the upper outer baffle is due to reflections of light from the plasma crown.

Fig. 5. Poloidal intensity distribution of the emission from doubly ionized carbon (CIII at 465 $\mathrm{nm}$ ) in the inner midplane above the equatorial plane (a) prior to and (b) with $\mathrm{CH}_{4}$ injection into L-mode plasmas.

Fig. 6. Poloidal profile of the measured ${ }^{13} \mathrm{C}$ surface deposition on tiles at the ceiling (a) and the lower divertor (b) for ${ }^{13} \mathrm{CH}_{4}$ injection into L-mode (black) and H-mode (red). Tile numbers of the abscissa correspond to the above layout. Two different analysis techniques, nuclear reaction analysis (NRA, solid symbols) and proton-induced gamma emission (PIGE, open symbols) are compared. Each data point of the NRA analysis represents the average of 12 poloidal measurements at three toroidal locations on a given tile.

Fig. 7. Intensity distributions of emission from doubly ionized carbon (CIII $465 \mathrm{~nm}$ ) (a, b) and deuterium atoms $\left(D_{\gamma} 434 \mathrm{~nm}\right)(\mathrm{c}, \mathrm{d})$ and in the lower divertor measured during the inter-ELM (a, c) and ELMing (b, d) phases. Separatrix (thick) and SOL flux surfaces spaced at $1 \mathrm{~cm}$ are shown in red, core flux surfaces spaced at $1 \mathrm{~cm}$ are shown in blue. Image data were taken at $1 \mathrm{~ms}$ integration time and sorted with respect to the ELM onset time calculated from a $20 \mathrm{kHz}$ fast $\mathrm{D}_{\alpha}$ signal. 
Fig. 8. Tomographic reconstruction of the emissions from (a) $\mathrm{CD} / \mathrm{CH}(432 \mathrm{~nm})$, (b) CII (515 nm), and (c) CIII (465 nm) in the plasma crown during $\mathrm{CH}_{4}$ injection into $\mathrm{H}$-mode. The red lines indicate the separatrix (thick) and poloidal flux contours in the SOL spaced at $1 \mathrm{~cm}$. Plasma-wall interaction was observed prior to the $\mathrm{CH}_{4}$ injection at the tip of the upper outer limiter at $(\mathrm{R}, \mathrm{Z})=(1.65 \mathrm{~m}, 1.07 \mathrm{~m})$.

Fig. 9. UEDGE radial distribution of the deuteron flux due to mass flow $\left(B_{\text {pol }} / B n_{i} v_{i, l l}\right)$ in the $\mathrm{SOL}$ at the crown for an attached $\mathrm{T}_{\mathrm{e}, \mathrm{ISP}}=3 \mathrm{eV}$ (black) and detached $\left(\mathrm{T}_{\mathrm{e}, \mathrm{ISP}}=1 \mathrm{eV}\right)$ (red) inner divertor leg. Positive flux is in the direction of the outer divertor plate.

Fig. 10. UEDGE distribution of CIII $(465 \mathrm{~nm})$ emission in the plasma crown $(\mathrm{a}, \mathrm{c})$ from the injected ${ }^{13} \mathrm{C}$, and from intrinsic ${ }^{12} \mathrm{C}$ and injected ${ }^{13} \mathrm{C}$ in the lower divertor $(\mathrm{b}, \mathrm{d})$. UEDGE simulations with an attached $\left(\mathrm{T}_{\mathrm{e}, \mathrm{ISP}}=3 \mathrm{eV}\right)(\mathrm{a}, \mathrm{b})$ and detached $\left(\mathrm{T}_{\mathrm{e}, \mathrm{ISP}}=1 \mathrm{eV}\right)(\mathrm{c}, \mathrm{d})$ inner divertor plasma are compared. 


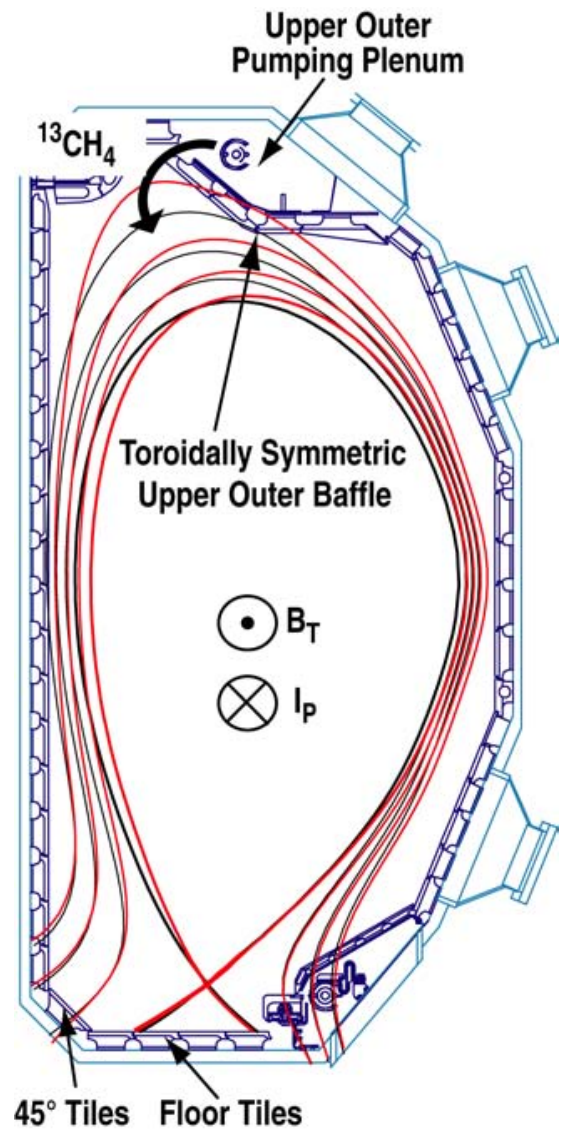

Fig. 1, M. Groth, Invited 48th APS/DPP 2006 


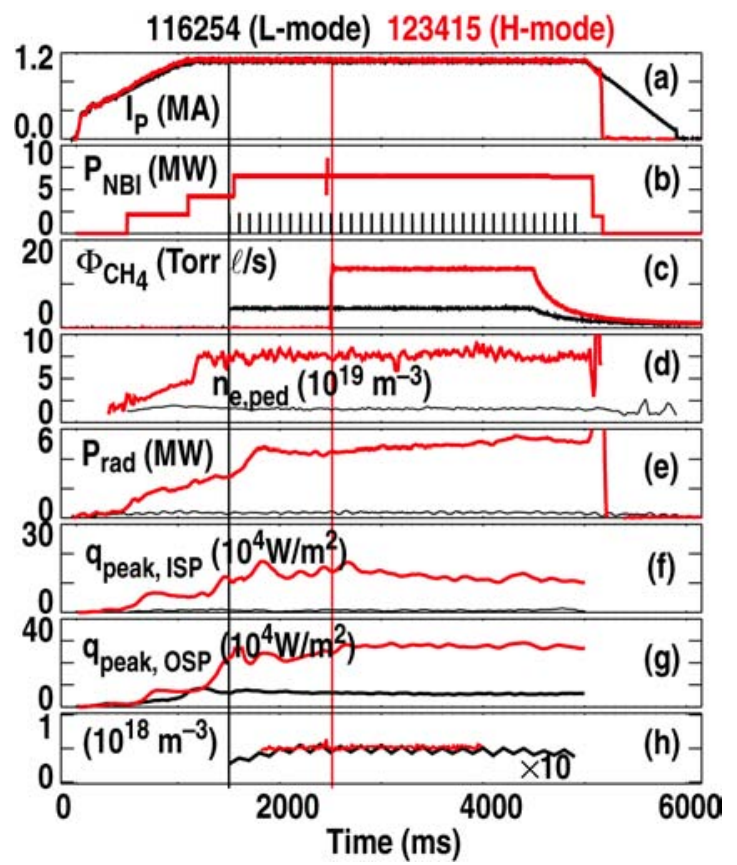

Fig. 2, M. Groth, Invited 48th APS/DPP 2006 


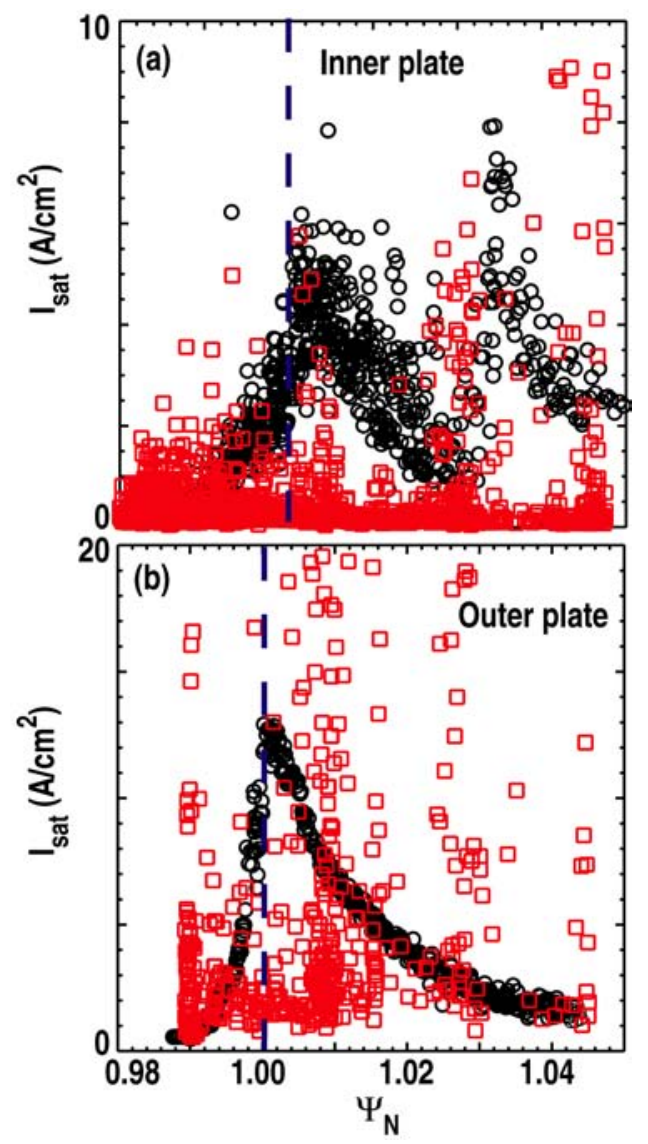

Fig. 3, M. Groth, Invited 48th APS/DPP 2006 

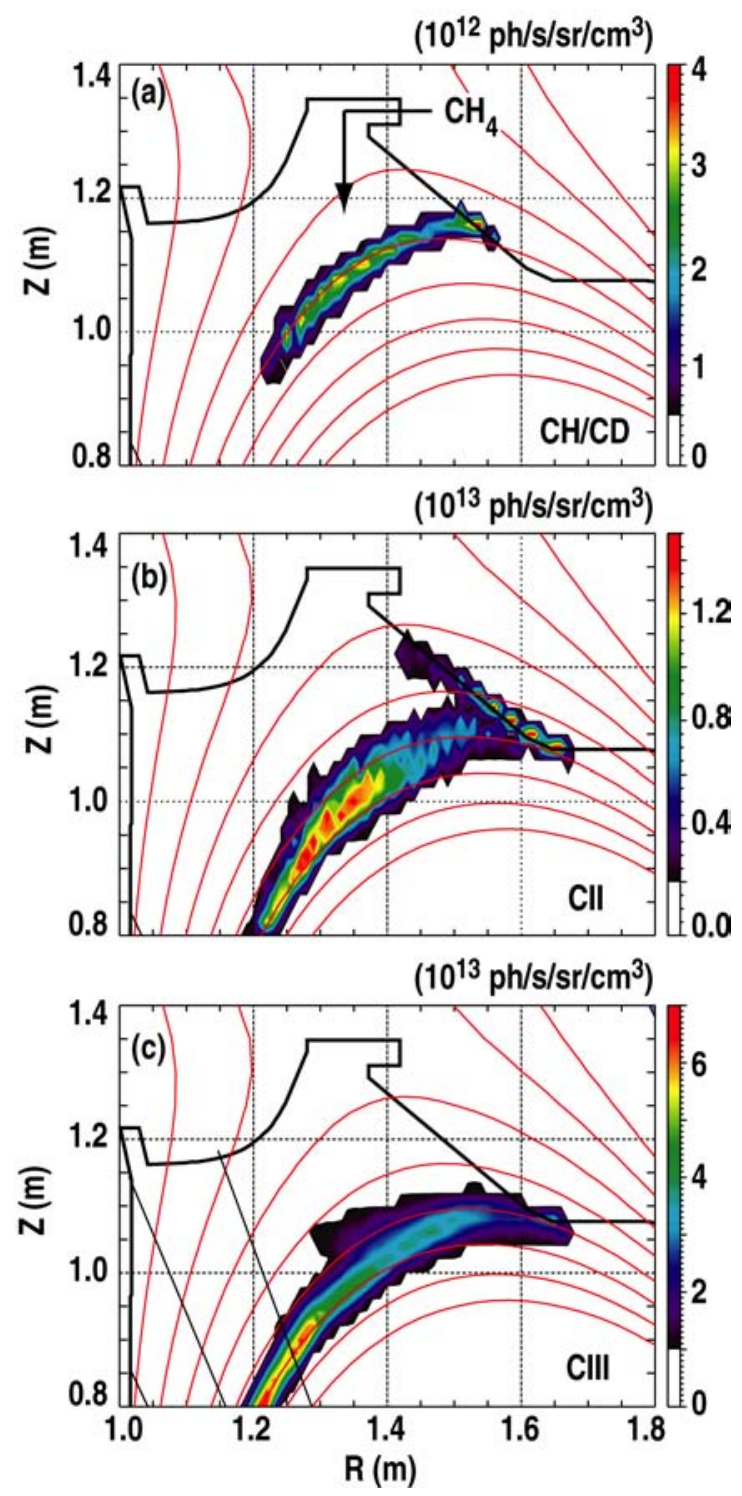

Fig. 4, M. Groth, Invited 48th APS/DPP 2006 


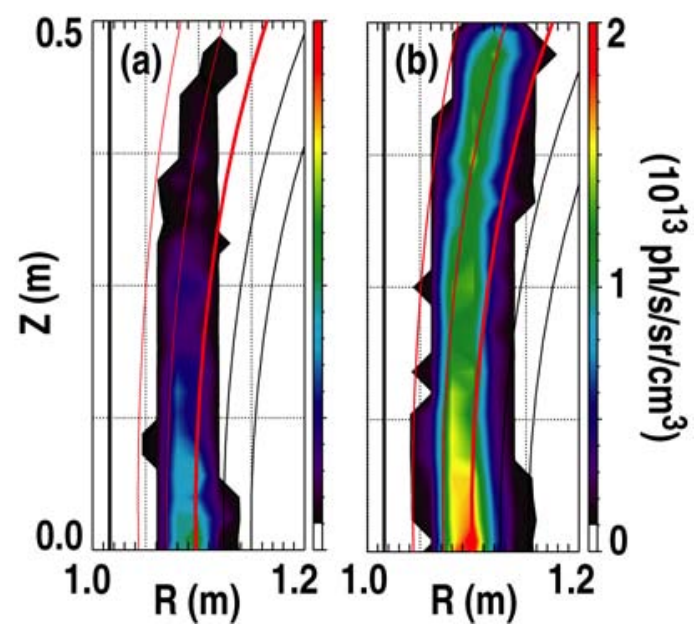

Fig. 5, M. Groth, Invited 48th APS/DPP 2006 
(a)
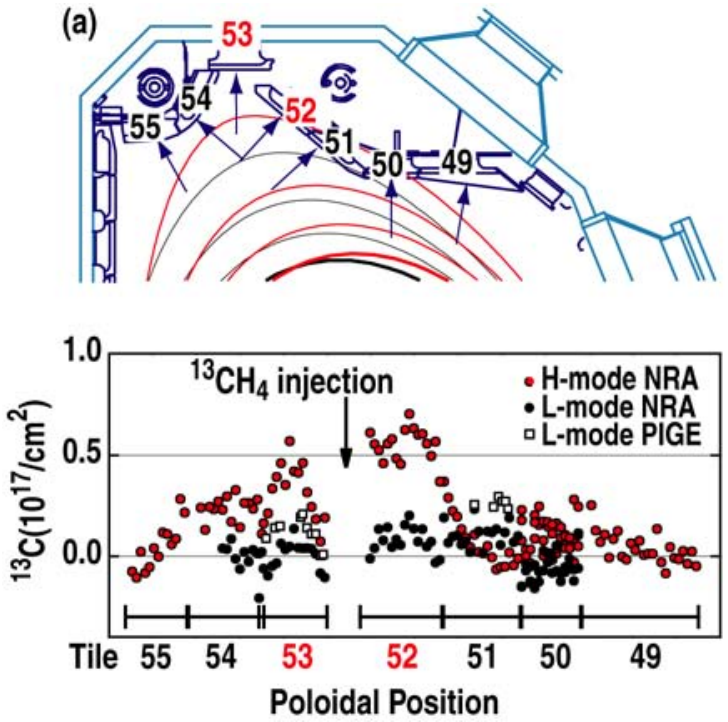

(b)
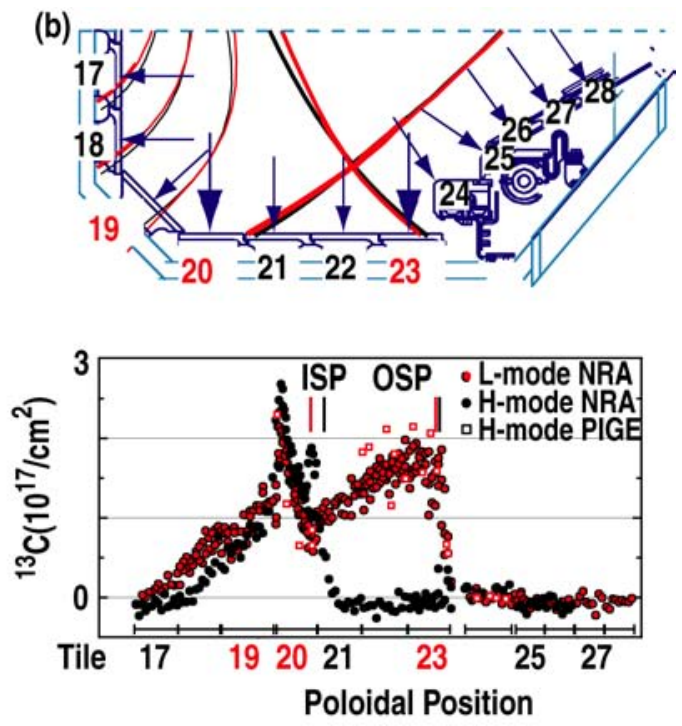

Fig. 6, M. Groth, Invited 48th APS/DPP 2006 

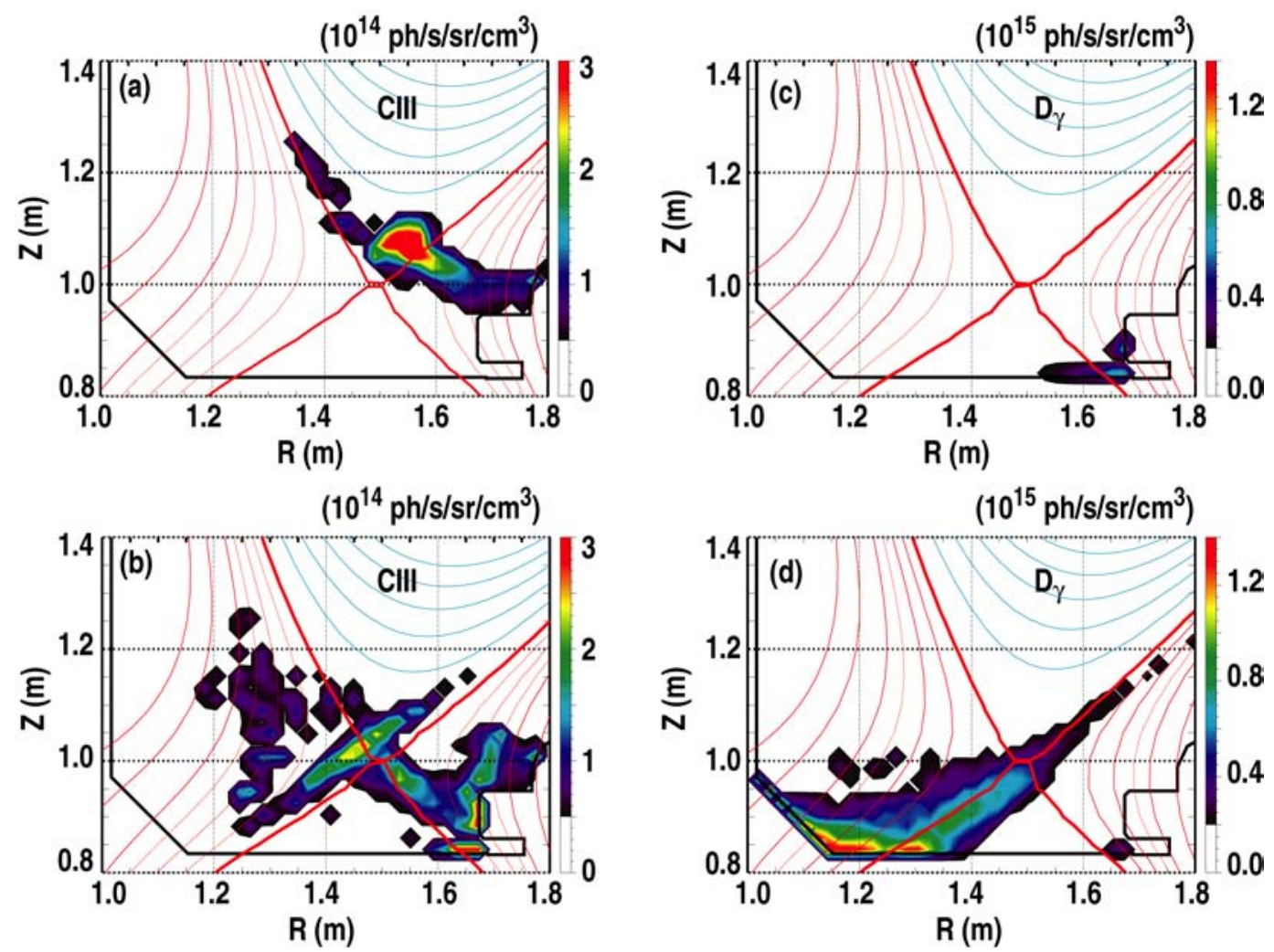

Fig. 7, M. Groth, Invited 48th APS/DPP 2006 

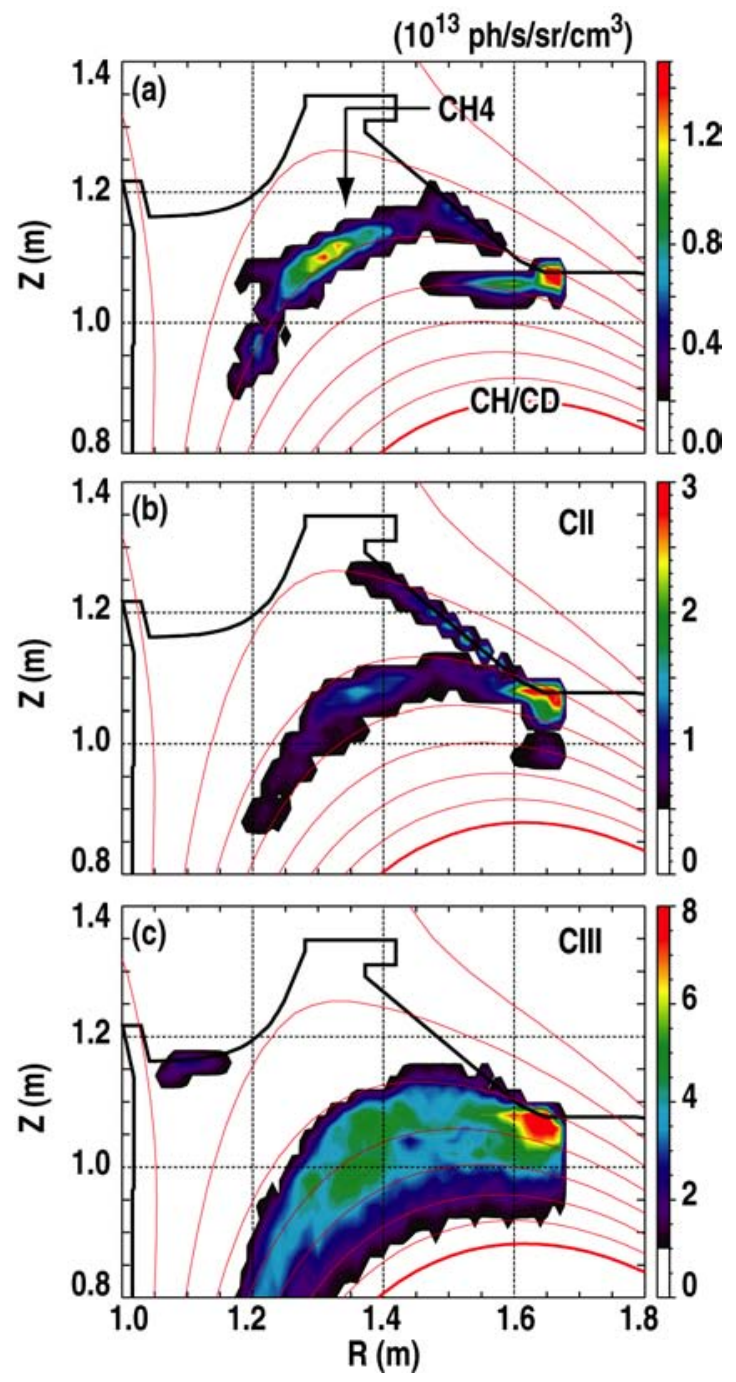

Fig. 8, M. Groth, Invited 48th APS/DPP 2006 


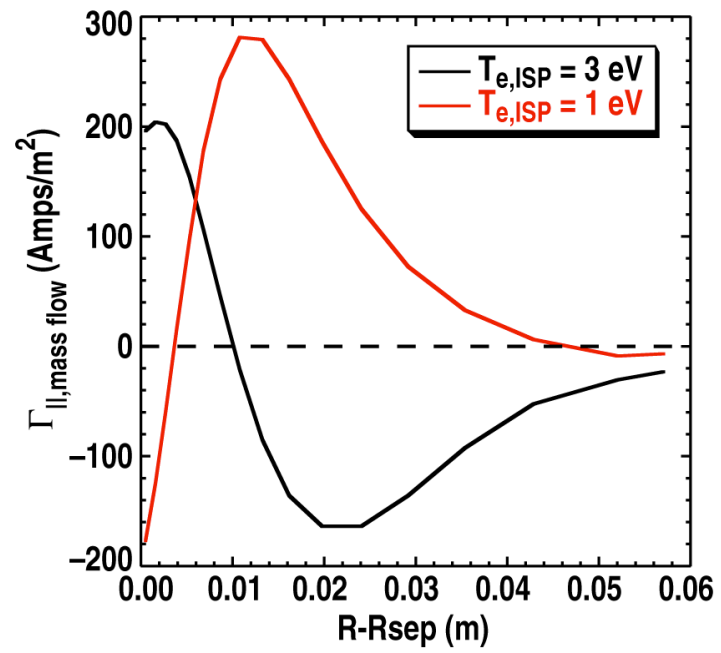

Fig. 9, M. Groth, Invited 48th APS/DPP 2006 

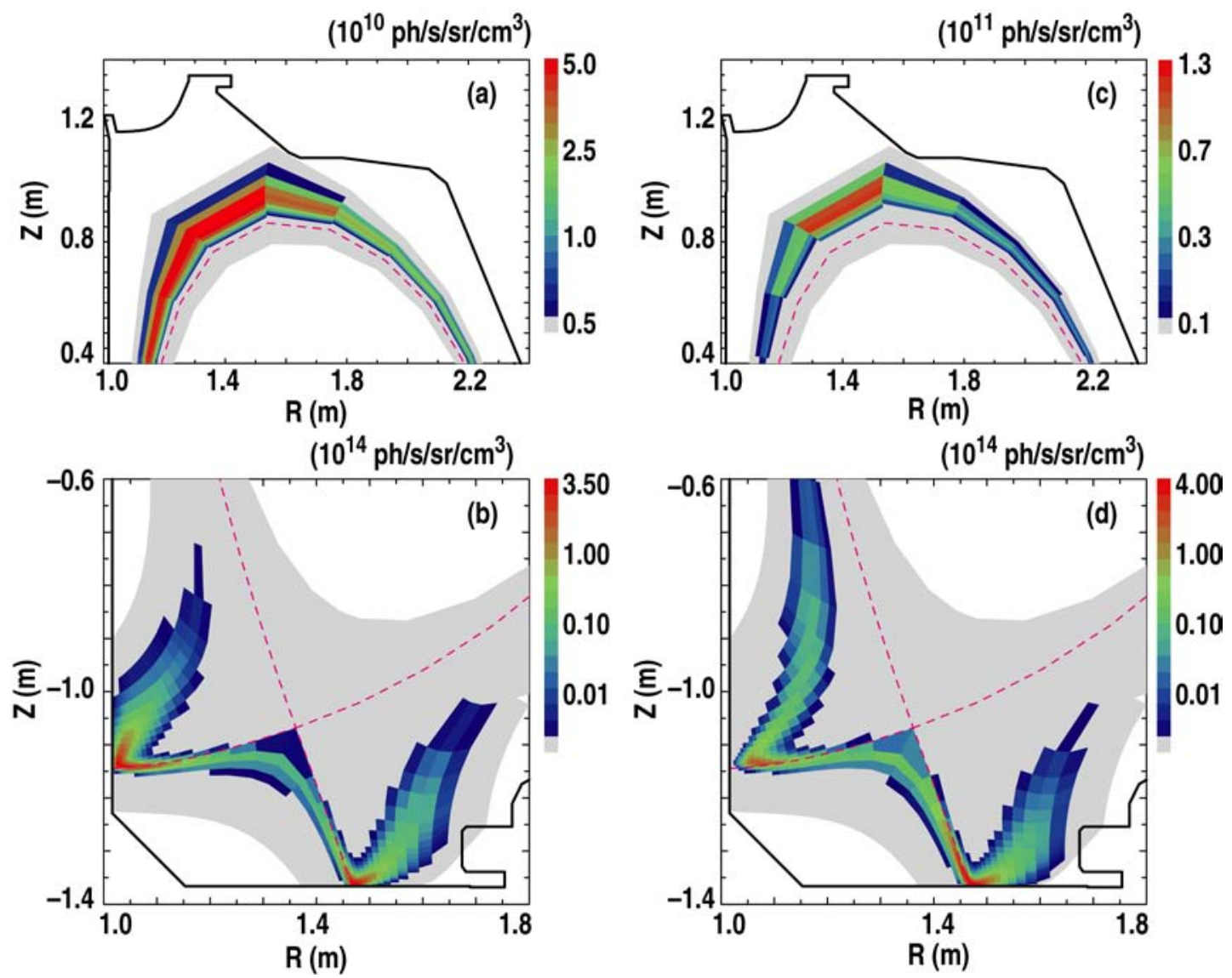

Fig. 10, M. Groth, Invited 48th APS/DPP 2006 